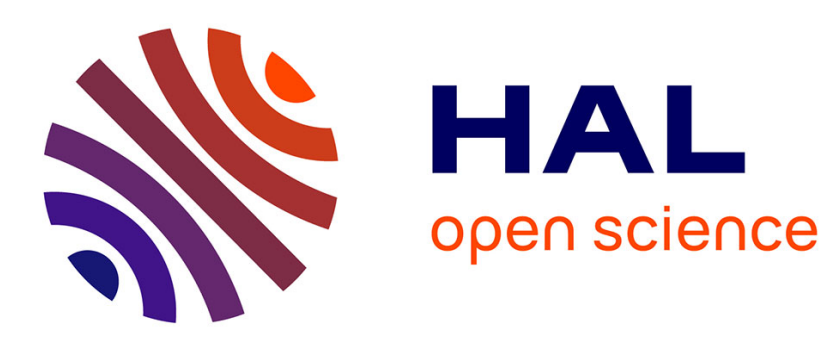

\title{
Thermal Risk Assessment of Levulinic Acid Hydrogenation to $\gamma$-Valerolactone
}

Yanjun Wang, Lamiae Vernières-Hassimi, Valeria Casson-Moreno, Jean-Pierre Hébert, Sébastien Leveneur

\section{- To cite this version:}

Yanjun Wang, Lamiae Vernières-Hassimi, Valeria Casson-Moreno, Jean-Pierre Hébert, Sébastien Leveneur. Thermal Risk Assessment of Levulinic Acid Hydrogenation to $\gamma$-Valerolactone. Organic Process Research and Development, 2018, 22 (9), pp.1092-1100. 10.1021/acs.oprd.8b00122 . hal-02435572

\section{HAL Id: hal-02435572}

https://hal-normandie-univ.archives-ouvertes.fr/hal-02435572

Submitted on 13 Jan 2022

HAL is a multi-disciplinary open access archive for the deposit and dissemination of scientific research documents, whether they are published or not. The documents may come from teaching and research institutions in France or abroad, or from public or private research centers.
L'archive ouverte pluridisciplinaire HAL, est destinée au dépôt et à la diffusion de documents scientifiques de niveau recherche, publiés ou non, émanant des établissements d'enseignement et de recherche français ou étrangers, des laboratoires publics ou privés. 


\section{Thermal risk assessment of levulinic acid hydrogenation to $\gamma$-valerolactone}

Yanjun Wang ${ }^{1}$, Lamiae Vernières-Hassimi ${ }^{1}$, Valeria Casson-Moreno ${ }^{3}$, Jean-Pierre Hébert ${ }^{1}$, Sébastien Leveneur ${ }^{1,2}$

${ }^{1}$ Normandie Univ, INSA Rouen, UNIROUEN, LSPC, EA4704, 76000 Rouen, France, E-mail : sebastien.leveneur@insa-rouen.fr

${ }^{2}$ Laboratory of Industrial Chemistry and Reaction Engineering, Johan Gadolin Process

Chemistry Centre, Åbo Akademi University, Biskopsgatan 8, FI-20500 Åbo/Turku, Finland.

${ }^{3}$ Dipartimento di Ingegneria Chimica, Civile, Ambientale e dei Materiali, Alma Mater Studiorum-Università di Bologna, via Terracini 28, 40131 Bologna, Italy 


\section{TOC graphic}

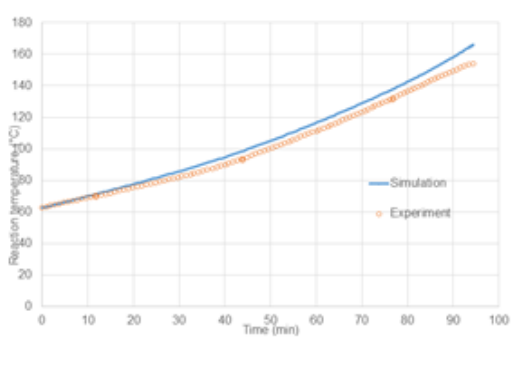

Estimation of kinetic and thermodynamic constants

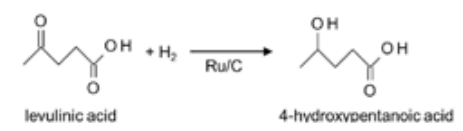

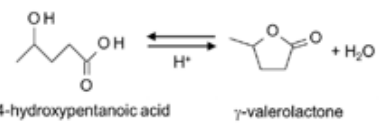

\begin{tabular}{|c|c|c|c|c|c|c|c|c|c|c|}
\hline RISK & \multicolumn{10}{|c|}{ [A mo/L } \\
\hline TP ${ }^{\circ} \mathrm{C}$ & 0.62 & 1.25 & 1.90 & 2.55 & 322 & 3.90 & 4.59 & 5.30 & 6.02 & 6.75 \\
\hline 100 & 6 & 5 & 4 & 8 & 8 & 8 & 8 & 8 & 6 & 6 \\
\hline 110 & 6 & 5 & 5 & 8 & 8 & 8 & 8 & 8 & 8 & 8 \\
\hline 115 & 6 & 5 & 5 & 10 & 8 & 8 & 8 & 8 & 8 & 8 \\
\hline 120 & 6 & 5 & 5 & 10 & 8 & 8 & 8 & 8 & 8 & 8 \\
\hline 125 & 6 & 5 & 5 & 10 & 10 & 8 & 8 & 8 & 8 & 8 \\
\hline 126 & 6 & 5 & 5 & 10 & 10 & 8 & 8 & 8 & 8 & 8 \\
\hline 127 & 6 & 5 & 5 & 10 & 10 & 8 & 8 & 8 & 8 & 8 \\
\hline 128 & 6 & 5 & 5 & 10 & 10 & 8 & 8 & 8 & 8 & 8 \\
\hline 129 & 6 & 5 & 5 & 10 & 10 & 10 & 8 & 8 & 8 & 8 \\
\hline 130 & 6 & 5 & 5 & 10 & 10 & 10 & 8 & 8 & 8 & 8 \\
\hline
\end{tabular}

Safe operating conditions

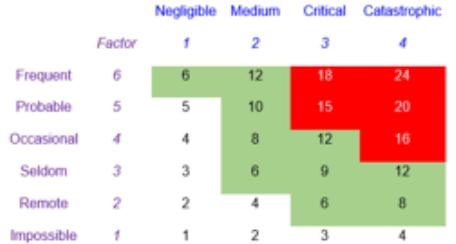

$\square$ Non-acceptatse $\square$ Madum $\square$ Neglizible Establishment of a thermal risk matrix 


\begin{abstract}
.
The use of biomass as feedstock to produce chemicals or biofuels is increasing. This renewable, biodegradable and ecofriendly feedstock could present some new risks that should be taken into account. In this context, a thermal risk assessment of levulinic acid (LA) hydrogenation to $\gamma$ valerolactone (GVL), which is a platform molecule produced from lignocellulosic biomass process, catalyzed by $\mathrm{Ru} / \mathrm{C}$ in water was performed .
\end{abstract}

A kinetic model including an energy balance under near-adiabatic conditions was built. For that, different experiments at different operating conditions (levulinic acid concentration and catalyst loading) were performed by using an Advanced Reactive System Screening Tool (ARSST) to estimate the kinetic constants of this reaction system. To make a thermal risk assessment of a chemical reaction system, two safety parameters should be defined: Time-to-Maximum Rate under adiabatic conditions $\left(\mathrm{TMR}_{\mathrm{ad}}\right)$ and adiabatic temperature rise $\left(\Delta \mathrm{T}_{\mathrm{ad}}\right)$. The parameter $\mathrm{TMR}_{\mathrm{ad}}$ defines the time to reach the maximum temperature rate and characterizes the probability of risk. The parameter $\Delta \mathrm{T}_{\mathrm{ad}}$ is the difference between the maximum and initial reaction temperature and characterizes the severity of risk. Based on this kinetic model, these two parameters were determined at different operating conditions. With the aid of a risk matrix, it was possible to determine the safe operating conditions (temperature, levulinic acid concentration, hydrogen pressure and catalyst loading).

Keywords: Thermal risk assessment, biomass valorization, hydrogenation, levulinic acid, $\gamma$ valerolactone, kinetic modeling 


\section{INTRODUCTION}

Due to fossil depletion, environmental issues, global warming and energy dependence from some fossil-energy-exporting countries, the development of processes and technologies for the production of energy from renewable sources is increasing worldwide. ${ }^{1}$ In particular, the use of any type of biomass as raw materials is intensely increasing, along with the number and potentiality of bioenergy production plants. ${ }^{2}$

For the valorization of biomass, the tendency is to work on the production of platform molecules. ${ }^{3}$ Furthermore, lignocellulosic biomass should be privileged because of its noncompetition with food. There are different potential platform molecules issued from lignocellulosic biomass like sorbitol, furfural, hydroxymethylfurfural (HMF), levulinic acid (LA), lignin monomer, ethanol, butanol or lactic acid. ${ }^{4,5}$ Levulinic acid is of particular interest, and has been identified as one of the twelve promising building blocks by the US department of energy. ${ }^{3}$

LA is used as solvent, antifreeze, food flavoring agent, intermediate for pharmaceuticals, and for plasticizers synthesis. ${ }^{6}$ As a platform molecule, levulinic acid can be transformed into different chemicals such as diphenolic acid (as replacement for bisphenol A in polycarbonates, epoxy resins, and other polymers, or being used in lubricants, adhesives, and paints), pentanoic acid, angelicalactones, 2-butanone or $\gamma$-valerolactone. 
Different processes have been developed for the production of LA from lignocellulosic biomass (LCB). ${ }^{7}$ One of the most consolidated technologies currently existing for LA industrial production is the Biofine process. ${ }^{8-10}$ By further hydrogenation reaction, LA can be converted to $\gamma$-valerolactone (GVL), which is in turn, a key platform molecule for the production of biochemicals/-fuels, and is the cornerstone of cascade processes for the production of liquid fuels. The steps of such process are depicted in Figure 1.

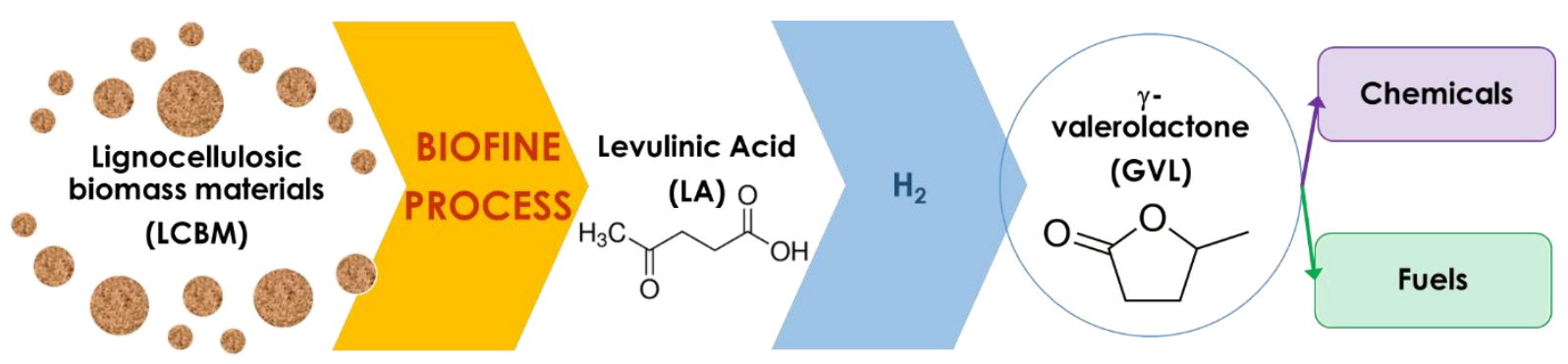

Figure 1. Steps of the valorization process of LCB biomass: the production of LA and its reduction to GVL.

Alonso et al. ${ }^{11}$ have also demonstrated that $\gamma$-valerolactone is a sustainable platform molecule. Several articles have shown the possibility to produce GVL by hydrogenation of aqueous solution of levulinic acid: the use of molecular hydrogen ${ }^{12-19}$ or the use of a hydrogen donor such as from the decomposition of formic acid ${ }^{20-22}$ or from alcohols such as ethanol and 2propanol. $^{23,24}$ This strategy avoids to implement a levulinic acid vaporization step or a dehydration step. From an economical, safety and energy point of view, this process should be developed for mild temperature and pressure conditions. This approach could elegantly reduce the number of processing steps and the operating cost. To this aim, different heterogeneous catalysts have been developed. Among various noble metals (for example Ru, Pt, Pd, Ir, Re, Rh, $\mathrm{Ni}$, etc.) supported on different materials $\left(\mathrm{Al}_{2} \mathrm{O}_{3}, \mathrm{SiO}_{2}, \mathrm{C}\right)$, $\mathrm{Ru}$ catalyst is particularly active and 
selective for this reaction. ${ }^{25-28}$ At the laboratory scale, one of the most efficient way of GVL production is the hydrogenation of aqueous $\mathrm{LA}$ with $\mathrm{H}_{2}$ over heterogeneous catalyst $\mathrm{Ru} / \mathrm{C}{ }^{29}$

The design and scale-up of new processes and technologies using biomass feedstock might involve emerging risks according to the International Risk Governance Council: issues that are perceived to be potentially significant, but they may not be fully understood and assessed and therefore correctly managed, e.g. bio-hazards, thermal risk and dust explosion.

On one hand, processes using biomass are usually perceived as thermally and/or toxicology safer or even completely harmless with respect to other conventional chemical processes. On the other hand, using biomass as a raw material entails hazardous materials and severe process conditions such as acid hydrolysis, high pressures and temperatures, and a risk assessment should be performed for these chemical processes. ${ }^{30,31}$ Society could accept such processes based on biomass, i.e., biorefinery, because it can promote new jobs, consume local biomass feedstock and waste, diminish the dependency towards fossil feedstock and use ecofriendly raw materials. Thus, to preserve the development of such sustainable industries and its image towards public opinion, risk assessment of these processes should be done.

For example, in the last decade, there have been several accidents involving bioenergy production and feedstock supply chain that raised concern on the safety of such technologies. ${ }^{32-}$ ${ }^{34}$ The analysis of major accidents showed that their number is growing faster than bioenergy production, and the comparison with the number of accidents in oil refining activities shows that the increasing trend is specific to bioenergy sector. ${ }^{32}$ 
Although different kinetic models for the hydrogenation of LA or alkyl levulinates by using $\mathrm{Ru} / \mathrm{C}$ are described in the literature ${ }^{12,14,29,35,36}$ none of them have investigated the thermal aspect of this reaction. One should keep in mind that hydrogenation of unsaturated compounds are exothermic reactions, and the risk of thermal runaway is not negligible. ${ }^{37,38}$ Reaction enthalpy for the hydrogenation of LA to GVL was found to be $-74.47 \mathrm{~kJ} \mathrm{~mol}^{-1}{ }^{39}$ This value cannot be neglected.

It has been demonstrated that thermal runaway is a major threat in chemical industry. ${ }^{40,41}$ In this panorama, thermal risk assessment for the hydrogenation of levulinic acid to $\gamma$-valerolactone catalyzed by $\mathrm{Ru} / \mathrm{C}$ in water was proposed in this paper (Figure 2). A kinetic model under nearadiabatic conditions was built based on a homogeneous batch reactor model and experiments performed in ARSST system. To make a thermal risk assessment, batch operation should be used because it is the most conservative system. Indeed, in batch process under adiabatic mode, thermal accumulation is higher compared to semi-batch or continuous process.

Then, the model was employed to determine the adiabatic temperature rise $\Delta \mathrm{T}_{\mathrm{ad}}$, which characterizes the severity of the thermal risk, and the Time-to-Maximum Rate under adiabatic conditions $\mathrm{TMR}_{\mathrm{ad}}$, which characterizes the probability of the thermal risk. The benefit of such approach is to be able to determine the safety parameters at different operating conditions which is not possible by using a zero-order approach. ${ }^{42}$ 
At last, a risk matrix based on severity and probability of thermal risk was created for thermal risk assessment at different reaction conditions including levulinic acid concentration, temperature, catalyst loading and hydrogen pressure.

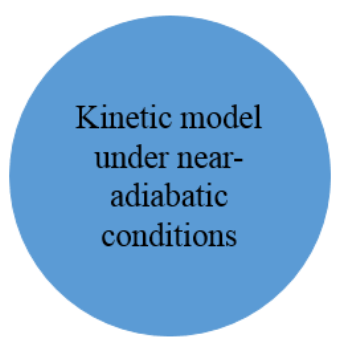

Step 1

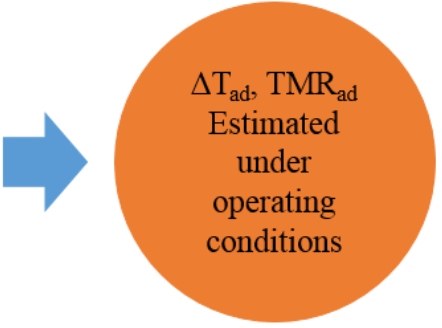

Step 2

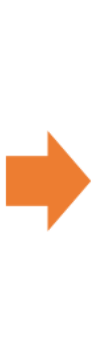

Thermal risk assessment

Step 3

Figure 2. Methodology of thermal risk assessment for hydrogenation of LA to GVL. 


\section{RESULTS AND DISCUSSION}

\subsection{Kinetic model}

Hydrogenation of levulinic acid to $\gamma$-valerolactone includes two steps: the first step is the hydrogenation of the ketone group of levulinic acid leading to the formation of 4hydroxypentanoic acid (HPA). The second step is the ring closure reaction of HPA to $\gamma$ valerolactone. ${ }^{14,35}$ The mechanism of hydrogenation of levulinic acid is illustrated in Figure 3.

Reaction 1: hydrogenation

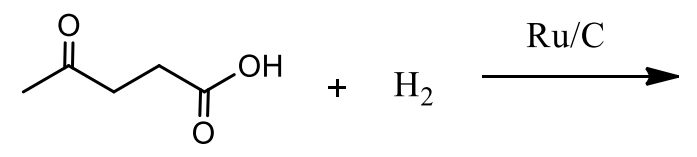

LA

Reaction 2: cyclization

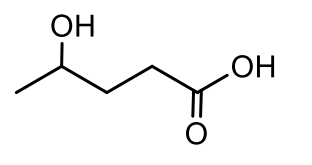

4-HPA
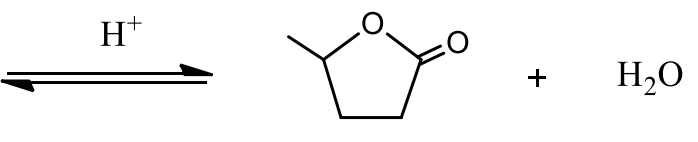

GVL

Figure 3. Reaction mechanism for the hydrogenation of levulinic acid to $\gamma$-valerolactone.

Piskun et al. ${ }^{35}$ have developed two models: one based on a Langmuir-Hinshelwood model for both reactions and the other one by assuming an equilibrium reaction for the ring-closure one.

One of the objectives of this article was to develop a kinetic model under adiabatic conditions, which takes into account the concentration of LA, proton, $\mathrm{H}_{2}$ pressure and catalyst loading. For that reason, the kinetic model of Piskun et al. ${ }^{35}$ describing the kinetic model as homogeneous model was used in this study. 
The hydrogenation of LA to HPA on the catalyst is described by a Langmuir-Hinshelwood model (eq 1).

$R_{1}=\frac{k_{1} \cdot P_{H_{2}} \cdot K_{L A} \cdot[L A]}{\left(1+K_{L A} \cdot[L A]+K_{G V L} \cdot[G V L]+K_{H P A} \cdot[H P A]\right)^{2}}$

where, $\mathrm{K}_{\mathrm{LA}}, \mathrm{K}_{\mathrm{GVL}}$ and $\mathrm{K}_{\mathrm{HPA}}$ are the adsorption coefficients for LA, GVL and HPA, respectively. These thermodynamic constants $\left(\mathrm{K}_{\mathrm{LA}}, \mathrm{K}_{\mathrm{GVL}}\right.$ and $\left.\mathrm{K}_{\mathrm{HPA}}\right)$, which do not depend on reactor characteristic, were assumed to be the same than the ones estimated by Piskun et al. ${ }^{32}$

As the first reaction depends on the heterogeneous catalyst and on the gas-liquid, liquid-solid mass transfers, thus this reaction is sensitive to the stirring system. For that reason, the kinetic constants for the first reaction, $\mathrm{k}_{1}\left(\mathrm{~T}_{\mathrm{Ref}}\right)$ and $\mathrm{Ea}_{1}$, were estimated in this work and compared to the ones obtained from the work of Piskun et al. ${ }^{35}$

For the second reaction, reversible transformation of HPA to GVL occurs in the bulk phase and is catalyzed by Brönsted acid. As the second reaction occurs in the bulk aqueous phase and does not involve the heterogeneous catalyst. Thus, this reaction can be considered to have the same kinetics in our system as the one of Piskun et al. ${ }^{35}$ Hence, in this work, the kinetic constants of the second reaction estimated by Piskun et al. ${ }^{35}$ were used.

Originally, Piskun et al. ${ }^{35}$ have described the reversible transformation of HPA to GVL as 2 reactions (direct and indirect reactions) occurring in the bulk phase and catalyzed by Brönsted acid. These two reactions can be summarized into one reaction and expressed as:

$$
R_{2}=k_{2} \cdot\left[H^{+}\right]\left([H P A]-\frac{1}{K_{2}}[G V L]\right)
$$


where, $\mathrm{K}_{2}$ is the equilibrium constant of the second reversible reaction and can be expressed as $K_{2}=\frac{k_{2}}{k_{-2}}$. According to Piskun et al., ${ }^{29}$ the concentration of protons can be expressed as:

$\left[H^{+}\right]=\sqrt{K_{L A}^{d i s s} \cdot[L A]+K_{H P A}^{d i s s} \cdot[H P A]}$

where, $K_{L A}^{\text {diss }}$ and $K_{H P A}^{\text {diss }}$ are the dissociation constants of levulinic acid and 4-hydroxypentanoic acid.

From the kinetic data of Piskun et al., ${ }^{29}$ it was possible to estimate $K_{2}$ by a van't Hoff law:

$K_{2}(T)=K_{2}\left(T=90^{\circ} \mathrm{C}\right) \cdot \exp \left(\frac{-\Delta H_{R, 2}}{R} \cdot\left(\frac{1}{T}-\frac{1}{90^{\circ} \mathrm{C}}\right)\right)$

It was found that at $90^{\circ} \mathrm{C}$, the value of $K_{2}\left(T=90^{\circ} \mathrm{C}\right)$ was equal to 10 and the reaction enthalpy $\Delta H_{R, 2}$ was found to be $-3.2 \mathrm{~kJ} / \mathrm{mol}$. 
2.2 Mass and energy balances for the system

Mass balance in the gas phase

Due to the high gas volume (ca. $400 \mathrm{~mL}$ ) compared to the liquid volume (ca. $10 \mathrm{~mL}$ ) and quite low variation of recorded pressure $(<1.4 \%)$, the variation of pressure in the ARSST was negligible. Thus, the system was considered to be under isobaric mode.

\section{Mass balance in the liquid phase}

Pressure of the gas phase was ca. 35 bar, thus the evaporation of the liquid phase had a minor effect on the mass balance. Mass balance for the different compounds present in the liquid phase can be expressed as:

$$
\begin{aligned}
& \frac{d C_{L A}}{d t}=-\frac{m_{c a t}}{V} R_{1} \\
& \frac{d C_{W}}{d t}=R_{2} \\
& \frac{d C_{G V L}}{d t}=R_{2} \\
& \frac{d C_{H P A}}{d t}=\frac{m_{c a t}}{V} R_{1}-R_{2}
\end{aligned}
$$




\section{Energy balance in the liquid phase}

Energy balance in the liquid phase is expressed as:

$\frac{d T}{d t}=$

$\frac{q_{r x}+q_{e l}}{m_{L A}(t) \cdot C_{P_{L A}}(T)+m_{W}(t) \cdot C_{P_{W}}(T)+m_{G V L}(t) \cdot C_{P_{G V L}}(T)+m_{H P A}(t) \cdot C_{P_{H P A}}(T)+m_{\text {cat }} \cdot C_{P_{\text {cat }}}(T)+m_{\text {insert }} \cdot C_{P_{\text {insert }}}(T)}$

$=$

$\frac{q_{r x}}{m_{L A}(t) \cdot C_{P_{L A}}(T)+m_{W}(t) \cdot C_{P W}(T)+m_{G V L}(t) \cdot C_{P G V L}(T)+m_{H P A}(t) \cdot C_{P H P A}(T)+m_{\text {cat }} \cdot C_{P_{\text {cat }}}(T)+m_{\text {insert }} \cdot C_{P \text { insert }}(T)}+$

$\beta$

The heat balance in the ARSST system includes the heat flow rate from the exothermic reactions $q_{r x}$ and the heat flow rate from the electrical heating $q_{e l}$.

Evolution of heat capacities with temperature for water, $\gamma$-valerolactone and levulinic acid were determined by using Aspen Plus software v9.0 (Aspen Technology, Inc.), using the PengRobinson with modified Huron-Vidal mixing rules thermodynamic model (Figure S1). This thermodynamic model was used based on the recommendation of Carlson. ${ }^{43}$ Due to the instability of HPA, it is difficult to measure its heat capacity. Thus, heat capacity of HPA was assumed to be the same as the one of GVL, because the chemical structure of HPA is similar to GVL.

In our model, we have taken into account the evolution of the different heat capacities with temperature and the variation of composition.

Heat capacity of catalyst was found to be equal to $1000 \mathrm{~J} /(\mathrm{kg} \mathrm{K}) .{ }^{44}$. Heat capacity of the inserts is equal to $837.36 \mathrm{~J} /(\mathrm{kg} \mathrm{K})$ according to the manufacturer. 
The heat flow-rate $q_{r x}$ due to the chemical exothermic reactions can be expressed as:

$q_{r x}=\left(-R_{1} \cdot \Delta H_{R, 1} \cdot \frac{m_{c a t}}{V_{l i q}}-R_{2} \cdot \Delta H_{R, 2}\right) \cdot V_{l i q}$

The determination of $\beta$, which is the background heating rate, was explained in the previous articles of our group. $^{42,45}$ This parameter was fixed for each experiments (Table 4).

The reaction enthalpy value $\Delta H_{R, 2}$ was found to be $-3.2 \mathrm{~kJ} / \mathrm{mol}$.

The enthalpies of formation for LA and GVL in liquid phase are $-678.64 \mathrm{~kJ} / \mathrm{mol}$ and -469.86 $\mathrm{kJ} / \mathrm{mol}$, respectively. ${ }^{39}$ The enthalpy of formation of water in liquid is $-285.3 \mathrm{~kJ} / \mathrm{mol} .{ }^{46}$ Thus, by knowing the second reaction enthalpy $\Delta H_{R, 2}$ and the enthalpies of formation of water and GVL, one can determine the enthalpy of formation of HPA, which is $-751.96 \mathrm{~kJ} / \mathrm{mol}$. Thus, the first reaction enthalpy value $\Delta H_{R, 1}$ is $-73.318 \mathrm{~kJ} / \mathrm{mol}$. Enthalpies of formation and of reaction are listed in Table 1. 
Table 1. Enthalpies of formation and of reaction. ${ }^{29,39}$

\begin{tabular}{|c|c|}
\hline Compound & Enthalpy of formation $(\mathrm{kJ} / \mathrm{mol})$ \\
\hline Levulinic acid (LA) & -678.64 \\
\hline$\gamma$-valerolactone (GVL) & -469.86 \\
\hline 4-hydroxy-pentanoic acid (HPA) & -751.96 \\
\hline Water $\left(\mathrm{H}_{2} \mathrm{O}\right)$ & -285.3 \\
\hline Reaction & $\Delta H_{R} \mathrm{~kJ} / \mathrm{mol}$ \\
\hline Reaction 1 & -73.318 \\
\hline Reaction 2 & -3.2 \\
\hline
\end{tabular}

\subsection{Kinetic model}

Eqs. (5)-(9) were solved out by using ODESSA algorithm ${ }^{47}$ through ModEst software. $^{48}$

A modified Arrhenius equation was used to express the rate constants:

$k_{i}\left(T_{R}\right)=k_{i}\left(T_{R e f}\right) \cdot \exp \left(\frac{-E a_{i}}{R}\left(\frac{1}{T_{R}}-\frac{1}{T_{R e f}}\right)\right)$

The objective function $\omega=\left(y_{\text {exp }}-y_{\text {model }}\right)^{2}$ was minimized by using Simplex and LevenbergMarquardt algorithms. The terms $y_{\text {exp }}$ and $y_{\text {model }}$ are the experimental and the simulated values of the observable. Reaction temperature was used as an observable value for the non-linear 
regression stage. The following parameters were estimated: $k_{1}\left(T_{R e f}\right)$ and $E a_{1}$. Table 2 shows the values of the estimated parameters with their standard deviations.

Table 2. Estimated and statistical data at $\mathrm{T}_{\mathrm{Ref}}=66.85^{\circ} \mathrm{C}$.

\begin{tabular}{|c|c|c|c|}
\cline { 3 - 4 } \multicolumn{2}{c|}{} & Estimated parameters & Standard error (\%) \\
\hline$k_{1}\left(T_{\text {Ref }}\right)$ & {$\left[\mathrm{mol} /\left(\mathrm{kg} \_\right.\right.$cat s bar $\left.)\right]$} & $6.16 \cdot 10^{-04}$ & 7.0 \\
\hline$E a_{1}$ & {$[\mathrm{~kJ} / \mathrm{mol}]$} & 45.0 & 3.6 \\
\hline \multicolumn{2}{|c|}{} & Kinetic constants from Piskun et al. ${ }^{35}$ \\
\hline$k_{2}\left(T_{R e f}\right)$ & {$[\mathrm{L} /(\mathrm{mol} \mathrm{s})]$} & $9.85 \cdot 10^{-2}$ \\
\hline$E a_{2}$ & {$[\mathrm{~kJ} / \mathrm{mol}]$} & 62.5 \\
\hline
\end{tabular}

The high value of the coefficient of determination, i.e., $95 \%$ and low values of standard deviation (Table 1) show that the model is reliable. Piskun et al. ${ }^{35}$ have found that the kinetic constant of reaction 1 was $1.24 .10^{-2} \mathrm{~mol} /\left(\mathrm{kg} \_\right.$cat $\mathrm{s}$ bar $)$ at $66.85^{\circ} \mathrm{C}$, and the associated activation energy Ea 1 was found to be $34.1 \mathrm{~kJ} / \mathrm{mol}$. Within the temperature range $66.85-106.85^{\circ} \mathrm{C}$, the ratio $\frac{\left(k_{1}\right)_{\text {from Piskun et } \text { al. }^{32}}}{\left(k_{1}\right)_{\text {from this work }}}$ is ca. 20.

Three factors can explain this difference:

-Difference of heterogeneous catalyst: $\mathrm{Ru} / \mathrm{C}$ catalyst (3 wt.\% $\mathrm{Ru}$ ) from Evonik for the study performed by Piskun et al. ${ }^{35}$ and $\mathrm{Ru} / \mathrm{C}$ catalyst (5 wt.\% Ru) from Alfa Aesar company for this study;

-Stirring system of Piskun et al. ${ }^{35}$ was more efficient (Ruschton type impeller); 
-Thermal mode was different. Piskun et al. ${ }^{35}$ have performed their experiments under isothermal mode, whereas in this study experiments were performed under near-adiabatic conditions. Furthermore, for this reaction system, by increasing the reaction temperature, the hydrogen solubility decreases. ${ }^{29}$ Hence, the kinetics of HPA production is slower leading to lower the heatflow rate due to chemical reactions.

Different experiments with different initial operating conditions, listed in Table 3, were performed to estimate the kinetic constants. Fitting of the model to the experimental data provided by ARSST were shown in Figures 4A-D. Generally, the model fits well with the experimental data and can be considered to predict correctly the temperature trend. There is a deviation when the LA concentration is low (Figure 4D), i.e., $2.67 \mathrm{~mol} / \mathrm{L}$. The reason may be because the concentration of proton is not taken into account for the hydrogenation, and it was shown that protons could inhibit the hydrogenation of $\mathrm{C}=\mathrm{O}$ bond and accelerates the reaction. ${ }^{49}$

Table 3. Experimental matrix for ARSST experiments under 35 bar of hydrogen.

\begin{tabular}{|c|c|c|c|c|c|c|}
\hline Run & $\begin{array}{c}\text { LA } \\
(\mathbf{m o l} / \mathbf{L})\end{array}$ & $\begin{array}{c}\text { Water } \\
(\mathbf{m o l} / \mathbf{L})\end{array}$ & $\begin{array}{c}\text { Catalyst } \\
(\mathbf{k g} / \mathbf{L})\end{array}$ & $\begin{array}{c}\text { Volume } \\
(\mathbf{L})\end{array}$ & $\begin{array}{c}\text { Initial temperature T1 } \\
\left({ }^{\circ} \mathbf{C}\right)\end{array}$ & $\begin{array}{c}\boldsymbol{\beta} \\
\left({ }^{\circ} \mathbf{C} / \mathbf{m i n}\right)\end{array}$ \\
\hline 1 & 6.5 & 18.79 & 0.015 & 0.0074 & 61.46 & 0.48 \\
\hline 2 & 5.46 & 24.66 & 0.02 & 0.0076 & 62.53 & 0.65 \\
\hline 3 & 5.43 & 24.85 & 0.027 & 0.0076 & 68.45 & 0.88 \\
\hline 4 & 5.5 & 24.42 & 0.013 & 0.0075 & 63.32 & 0.43 \\
\hline 5 & 2.67 & 40.47 & 0.006 & 0.0078 & 68.3 & 0.68 \\
\hline 6 & 3.86 & 33.58 & 0.029 & 0.0078 & 71.35 & 1.11 \\
\hline
\end{tabular}




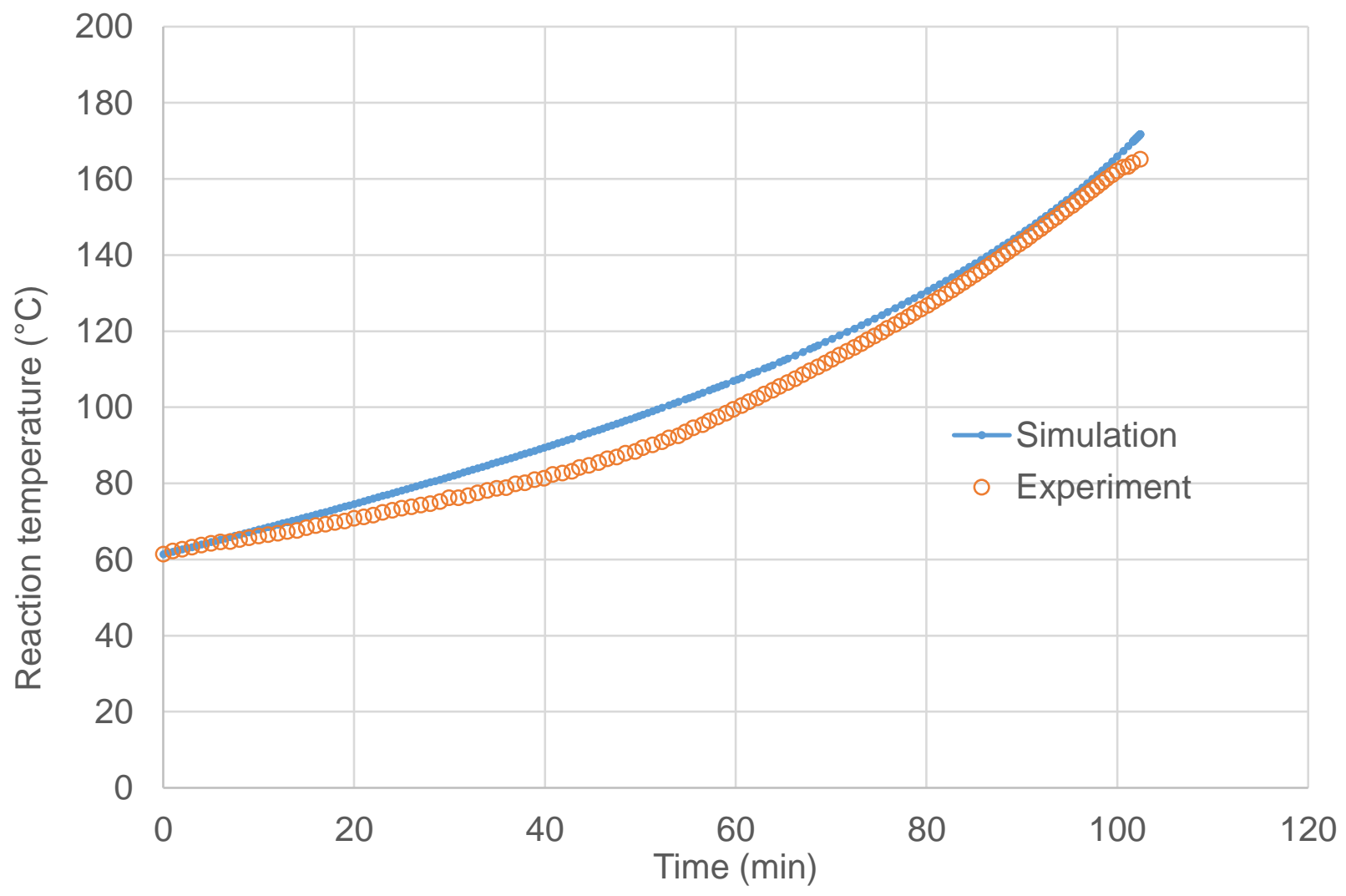

Figure 4A. Fit of the model to the experimental data for Run 1. 


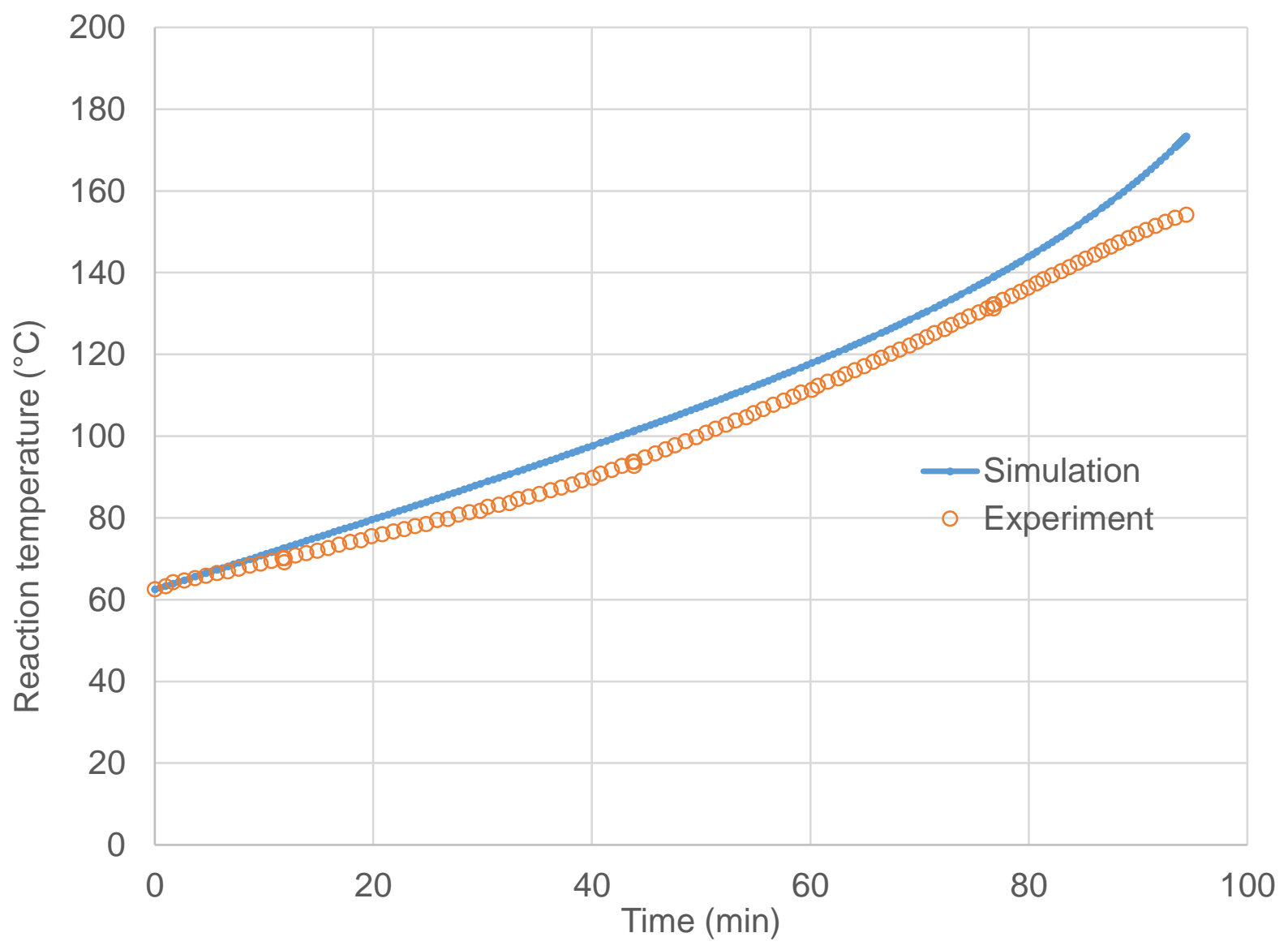

Figure 4B. Fit of the model to the experimental data for Run 2. 


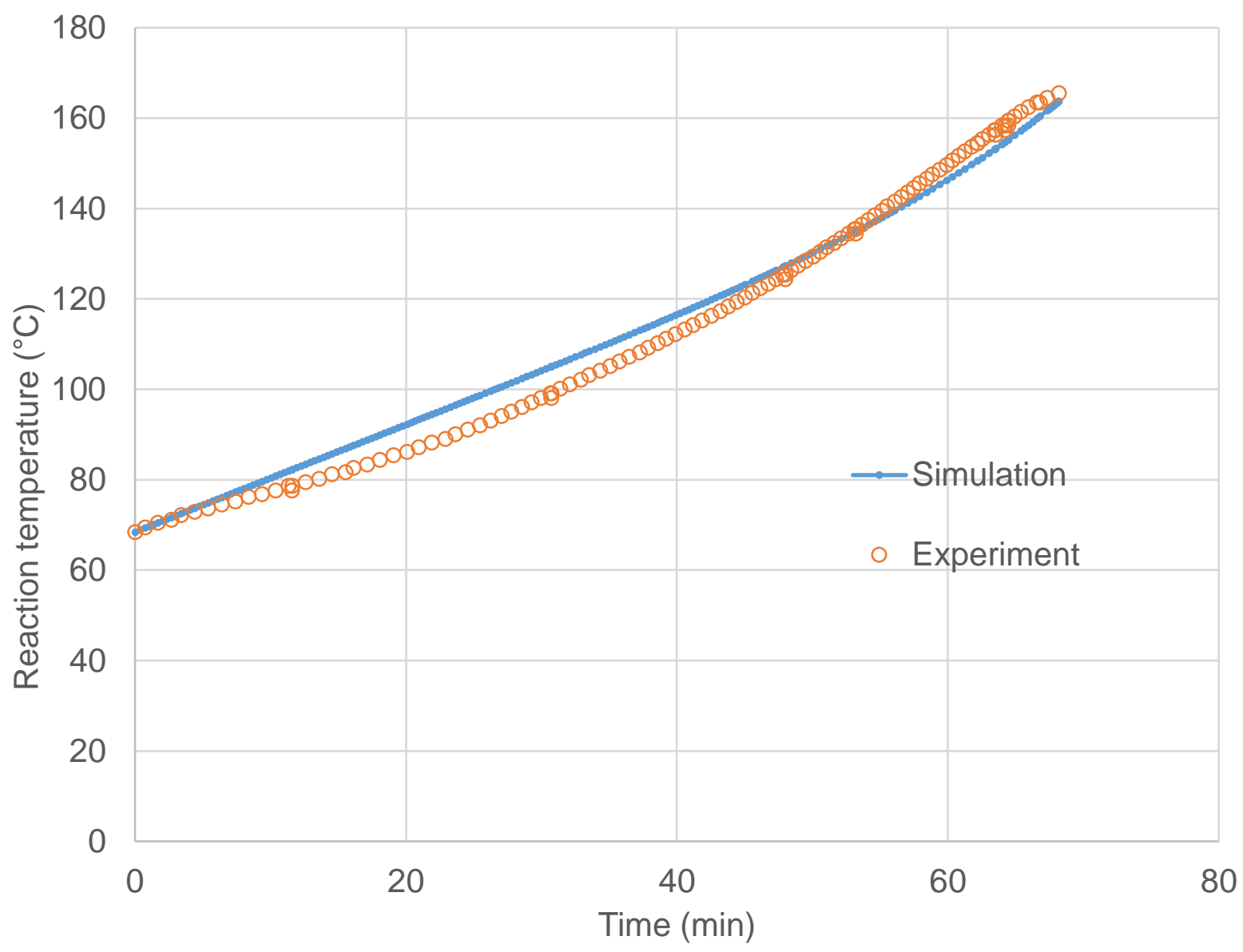

Figure 4C. Fit of the model to the experimental data for Run 3. 


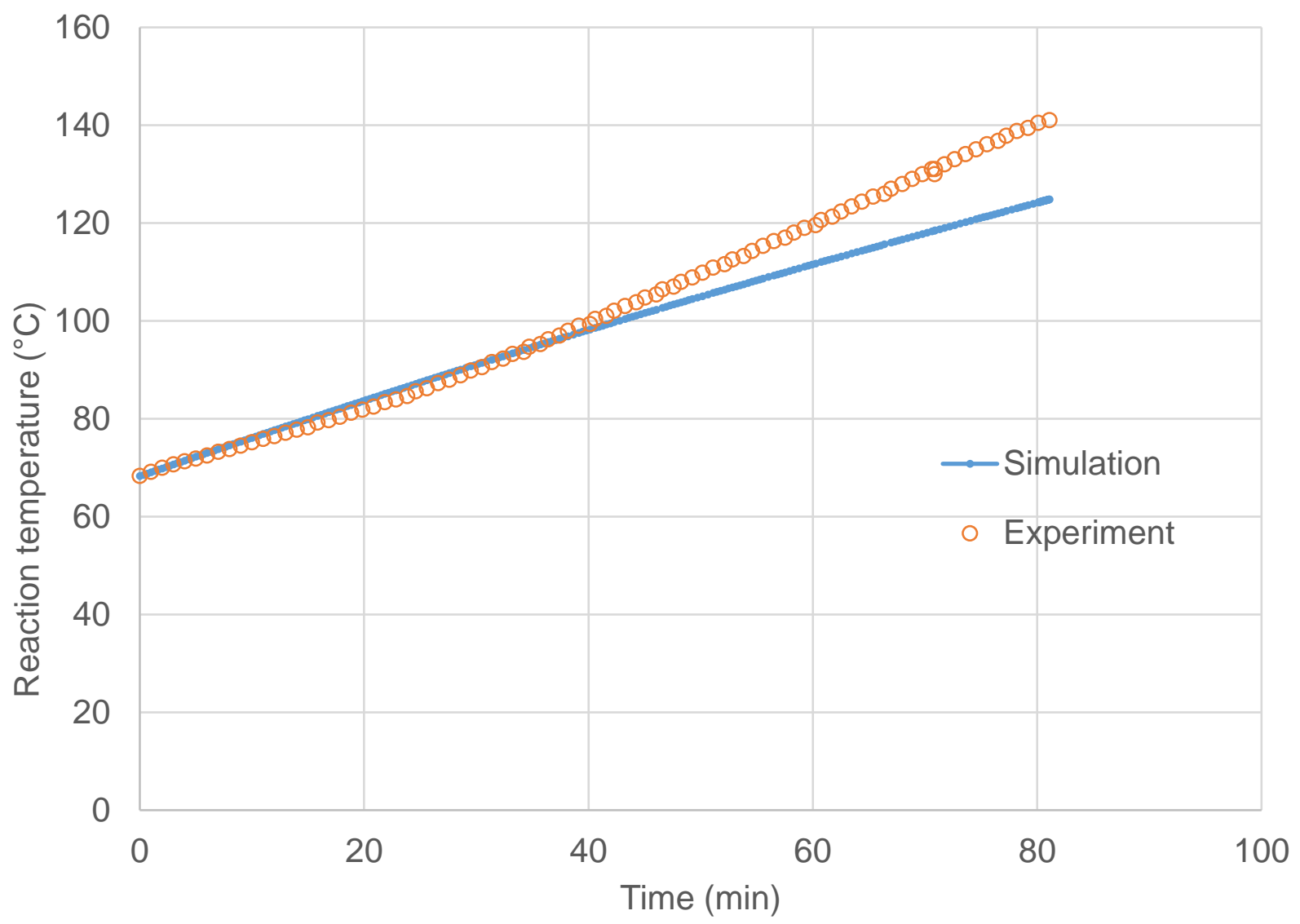

Figure 4D. Fit of the model to the experimental data for Run 5. 


\subsection{Thermal risk assessment.}

Thermal risk assessment is based on the determination of probability and severity of a thermal runaway. For that, it is important to determine the value of $\mathrm{TMR}_{\mathrm{ad}}$ at the process temperature and the value of the adiabatic temperature rise $\Delta \mathrm{T}_{\mathrm{ad}}$.

Stoessel ${ }^{50}$ has established some criteria for the values of $\Delta \mathrm{T}_{\mathrm{ad}}($ Table 4$)$ and $\mathrm{TMR}_{\mathrm{ad}}$ (Table 5). For instance, when the $\mathrm{TMR}_{\mathrm{ad}}$ value for a chemical process is lower than one hour, thus the probability of thermal runaway is frequent. When this value is higher than one hundred hours the probability can be considered as impossible. In the same spirit, when the adiabatic temperature rise $\Delta \mathrm{T}_{\mathrm{ad}}$ was found to be higher than $400^{\circ} \mathrm{C}$, then the severity of the thermal risk can be assumed to be catastrophic, and when this value is lower than $50^{\circ} \mathrm{C}$, then the severity can be assumed to be negligible because the reactor structure could support this temperature increase.

To assess the thermal risk of a chemical process at a defined operating condition, one needs to estimate the products of severity by probability. ${ }^{51}$ For that reason, a factor was attributed to each situation. When the severity and probability of thermal risk was negligible or impossible then a factor one was attributed (Tables 4 and 5).

By using the factors (Tables 4 and 5), it is possible to create a risk matrix for thermal runaway presented in Table 6 according to guidelines for designing risk matrices. ${ }^{51}$ When the value obtained from $\mathrm{TMR}_{\mathrm{ad}}$ factor multiplied by $\Delta \mathrm{T}_{\mathrm{ad}}$ factor is higher than 12 , then the risk can be assumed to be non-acceptable (red zone in Table 6). In that case, the manager should modify this installation or implement risk reduction measure. When the value is between 6 and 12, the thermal risk can be assumed to be medium (green zone in Table 6), which also needs risk 
management and safety control. When the value is lower than 6 , the thermal risk can be assumed to be negligible (white zone in Table 6).

Table 4. Assessment criteria for $\Delta \mathrm{T}_{\mathrm{ad}}{ }^{50}$

\begin{tabular}{|c|c|c|}
\hline Severity & $\boldsymbol{\Delta} \mathbf{T}_{\text {ad }}\left({ }^{\circ} \mathbf{C}\right)$ & Factor \\
\hline Catastrophic & $>400^{\circ} \mathrm{C}$ & 4 \\
\hline Critical & $200-400^{\circ} \mathrm{C}$ & 3 \\
\hline Medium & $50-200$ & 2 \\
\hline Negligible & 50 and no pressure & 1 \\
\hline
\end{tabular}

Table 5. Assessment criteria for $\mathrm{TMR}_{\mathrm{ad} .}{ }^{50}$

\begin{tabular}{|c|c|c|}
\hline Probability & TMR ad (hrs) & Factor \\
\hline Frequent & $<1$ & 6 \\
\hline Probable & 1 to 8 & 5 \\
\hline Occasional & 8 to 24 & 4 \\
\hline Seldom & 24 to 50 & 3 \\
\hline Remote & 50 to 100 & 2 \\
\hline Impossible & $>100$ & 1 \\
\hline
\end{tabular}


To study thermal risk assessment for this reaction, effects of LA concentration, temperature and catalyst loading were investigated under constant hydrogen pressure. The two safety parameters $\mathrm{TMR}_{\mathrm{ad}}$ and $\Delta \mathrm{T}_{\mathrm{ad}}$ were determined by using the developed kinetic model under near-adiabatic condition in this paper. $\mathrm{TMR}_{a d}$ at a process temperature $\mathrm{T}_{\mathrm{p}}$ was measured as the time difference between the maximum of $\left(\frac{\mathrm{dT}}{\mathrm{dt}}\right)_{\max }$ and the initial time. The parameter $\Delta \mathrm{T}_{\mathrm{ad}}$ was calculated as the temperature difference between the maximum temperature reached during the reaction and the initial temperature, i.e., the process temperature $T_{p}$.

Table 6. Risk matrix for a thermal runaway.

\begin{tabular}{cccccc} 
& Severity & Negligible & Medium & Critical & Catastrophic \\
Probability & Factor & 1 & 2 & 3 & 4 \\
Frequent & 6 & 6 & 12 & 18 & 24 \\
Probable & 5 & 5 & 10 & 15 & 20 \\
Occasional & 4 & 4 & 8 & 12 & 16 \\
Seldom & 3 & 3 & 6 & 9 & 12 \\
Remote & 2 & 2 & 4 & 6 & 8 \\
Impossible & 1 & 1 & 2 & 3 & 4 \\
& \multicolumn{7}{c}{ Non-acceptable } & & & & \\
& & & &
\end{tabular}


In this paper, the safety parameters were determined by simulation with varying the catalyst loading from 0.0001 to $0.14 \mathrm{~kg} / \mathrm{L}$, the process temperature from 100 to $130^{\circ} \mathrm{C}$, the initial levulinic acid concentration from 0.62 to $6.75 \mathrm{~mol} / \mathrm{L}$ and hydrogen pressure from 15 to 50 bar.

Tables 6A-D show the variation of the thermal risk for hydrogenation of LA to GVL under 35 bar at different catalyst loadings: $0.0001,0.0014,0.014$ and $0.14 \mathrm{~kg} / \mathrm{L}$, respectively. One can notice that when the catalyst loading is lower than $0.0001 \mathrm{~kg} / \mathrm{L}$, the thermal risk is almost negligible (Table 6A). The thermal risk is medium when the concentration is of $0.62 \mathrm{~mol} / \mathrm{L}$, because the kinetics is faster due to a higher amount of active sites (from the catalyst) compared to the amount of LA. Nevertheless, the estimated adiabatic temperature rise was found to be negligible, i.e., lower than $12^{\circ} \mathrm{C}$.

When the catalyst loading is in the range of $0.0014-0.014 \mathrm{~kg} / \mathrm{L}$, the thermal risk is medium in the majority of cases according to the risk matrix (Tables 6B-D). Generally, by increasing the catalyst loading, temperature and LA concentration, the thermal risk increases, which makes this process less safe. For example, when LA concentration is of $6.75 \mathrm{~mol} / \mathrm{L}$, in the temperature range of $100-130^{\circ} \mathrm{C}$, by increasing the catalyst loading from 0.0014 to $0.14 \mathrm{~kg} / \mathrm{L}$, the thermal risk value of this process increases from 8 to 12 . When LA concentration is of $3.22 \mathrm{~mol} / \mathrm{L}$ and catalyst loading is $0.0014 \mathrm{~kg} / \mathrm{L}$, by increasing the temperature from 100 to $130^{\circ} \mathrm{C}$, the thermal risk value increases from 8 to 10 (Table 6B). Some safety barriers should be included to prevent such medium risk, specifically if one cannot use different operating conditions for productivity reasons. When the risk is defined as medium and it is not possible to modify the operating conditions, the following safety barriers could be used: rupture disk to avoid the explosion of the reactor structure, install additional heat carrier pump to avoid any cooling failure and/or to implement an emergency cooling system to slow down the reaction temperature increase. 
However, by adjusting LA concentration between 1.25 and $1.90 \mathrm{~mol} / \mathrm{L}$, the thermal risk is negligible as $\mathrm{TMR}_{\mathrm{ad}}$ is more than $1 \mathrm{hr}$ and $\Delta \mathrm{T}_{\mathrm{ad}}$ is lower than $50^{\circ} \mathrm{C}$.

Effect of hydrogen pressure were also investigated for thermal risk assessment of this process. At a catalyst loading of $0.014 \mathrm{~kg} / \mathrm{L}$, by elevating the pressure from 15 to 50 bar, thermal risk is medium in the majority of cases (Tables 7A-B). Compared with Table 5C, which shown the same catalyst loading under 35 bar, the thermal risk kept the same value in most cases in the LA concentration range of $0.62-1.90 \mathrm{~mol} / \mathrm{L}$ due to lower $\Delta \mathrm{T}_{\text {ad. }}$. However, when $\mathrm{LA}$ concentration is higher than $1.90 \mathrm{~mol} / \mathrm{L}$, by elevating the hydrogen pressure from 15 to $50 \mathrm{bar}$, the thermal risk increases from 10 to 12 gradually because of higher hydrogen solubility which can accelerate the reactions.

Table 6A. Evolution of thermal risk in function of process temperature and LA concentration at a catalyst loading of $0.0001 \mathrm{~kg} / \mathrm{L}$ under $35 \mathrm{bar}_{2}$ (Medium Negligible)

\begin{tabular}{|c|c|c|c|c|c|c|c|c|c|c|}
\hline RISK & \multicolumn{10}{|c|}{$[L A] \mathrm{mo} / \mathrm{L}$} \\
\hline$T p^{\circ} \mathrm{C}$ & 0.62 & 1.25 & 1.90 & 2.55 & 3.22 & 3.90 & 4.59 & 5.30 & 6.02 & 6.75 \\
\hline 100 & $\mathbf{6}$ & $\mathbf{3}$ & $\mathbf{2}$ & $\mathbf{2}$ & $\mathbf{2}$ & $\mathbf{2}$ & $\mathbf{2}$ & $\mathbf{2}$ & $\mathbf{2}$ & $\mathbf{2}$ \\
\hline 110 & $\mathbf{6}$ & $\mathbf{3}$ & $\mathbf{2}$ & $\mathbf{4}$ & $\mathbf{2}$ & $\mathbf{2}$ & $\mathbf{2}$ & $\mathbf{2}$ & $\mathbf{2}$ & $\mathbf{2}$ \\
\hline 115 & $\mathbf{6}$ & $\mathbf{4}$ & $\mathbf{2}$ & $\mathbf{4}$ & $\mathbf{4}$ & $\mathbf{2}$ & $\mathbf{2}$ & $\mathbf{2}$ & $\mathbf{2}$ & $\mathbf{2}$ \\
\hline 120 & $\mathbf{6}$ & $\mathbf{4}$ & $\mathbf{3}$ & $\mathbf{4}$ & $\mathbf{4}$ & $\mathbf{2}$ & $\mathbf{2}$ & $\mathbf{2}$ & $\mathbf{2}$ & $\mathbf{2}$ \\
\hline 125 & $\mathbf{6}$ & $\mathbf{4}$ & $\mathbf{3}$ & $\mathbf{4}$ & $\mathbf{4}$ & $\mathbf{4}$ & $\mathbf{4}$ & $\mathbf{2}$ & $\mathbf{2}$ & $\mathbf{2}$ \\
\hline 126 & $\mathbf{6}$ & $\mathbf{4}$ & $\mathbf{3}$ & $\mathbf{4}$ & $\mathbf{4}$ & $\mathbf{4}$ & $\mathbf{4}$ & $\mathbf{2}$ & $\mathbf{2}$ & $\mathbf{2}$ \\
\hline 127 & $\mathbf{6}$ & $\mathbf{4}$ & $\mathbf{3}$ & $\mathbf{6}$ & $\mathbf{4}$ & $\mathbf{4}$ & $\mathbf{4}$ & $\mathbf{2}$ & $\mathbf{2}$ & $\mathbf{2}$ \\
\hline 128 & $\mathbf{6}$ & $\mathbf{4}$ & $\mathbf{3}$ & $\mathbf{6}$ & $\mathbf{4}$ & $\mathbf{4}$ & $\mathbf{4}$ & $\mathbf{2}$ & $\mathbf{2}$ & $\mathbf{2}$ \\
\hline 129 & $\mathbf{6}$ & $\mathbf{4}$ & $\mathbf{3}$ & $\mathbf{6}$ & $\mathbf{4}$ & $\mathbf{4}$ & $\mathbf{4}$ & $\mathbf{4}$ & $\mathbf{2}$ & $\mathbf{2}$ \\
\hline 130 & $\mathbf{6}$ & $\mathbf{4}$ & $\mathbf{3}$ & $\mathbf{6}$ & $\mathbf{4}$ & $\mathbf{4}$ & $\mathbf{4}$ & $\mathbf{4}$ & $\mathbf{2}$ & $\mathbf{2}$ \\
\hline
\end{tabular}


Table 6B. Evolution of thermal risk in function of process temperature and LA concentration at a catalyst loading of $0.0014 \mathrm{~kg} / \mathrm{L}$ under $35 \mathrm{bar} \mathrm{H}_{2}$ (Medium Negligible).

\begin{tabular}{|c|c|c|c|c|c|c|c|c|c|c|}
\hline RISK & \multicolumn{10}{|c|}{$[L A] \mathrm{mol} / \mathrm{L}$} \\
\hline$T p{ }^{\circ} \mathrm{C}$ & 0.62 & 1.25 & 1.90 & 2.55 & 3.22 & 3.90 & 4.59 & 5.30 & 6.02 & 6.75 \\
\hline 100 & $\mathbf{6}$ & $\mathbf{5}$ & $\mathbf{4}$ & $\mathbf{8}$ & $\mathbf{8}$ & $\mathbf{8}$ & $\mathbf{8}$ & $\mathbf{8}$ & $\mathbf{6}$ & $\mathbf{6}$ \\
\hline 110 & $\mathbf{6}$ & $\mathbf{5}$ & $\mathbf{5}$ & $\mathbf{8}$ & $\mathbf{8}$ & $\mathbf{8}$ & $\mathbf{8}$ & $\mathbf{8}$ & $\mathbf{8}$ & $\mathbf{8}$ \\
\hline 115 & $\mathbf{6}$ & $\mathbf{5}$ & $\mathbf{5}$ & $\mathbf{1 0}$ & $\mathbf{8}$ & $\mathbf{8}$ & $\mathbf{8}$ & $\mathbf{8}$ & $\mathbf{8}$ & $\mathbf{8}$ \\
\hline 120 & $\mathbf{6}$ & $\mathbf{5}$ & $\mathbf{5}$ & $\mathbf{1 0}$ & $\mathbf{8}$ & $\mathbf{8}$ & $\mathbf{8}$ & $\mathbf{8}$ & $\mathbf{8}$ & $\mathbf{8}$ \\
\hline 125 & $\mathbf{6}$ & $\mathbf{5}$ & $\mathbf{5}$ & $\mathbf{1 0}$ & $\mathbf{1 0}$ & $\mathbf{8}$ & $\mathbf{8}$ & $\mathbf{8}$ & $\mathbf{8}$ & $\mathbf{8}$ \\
\hline 126 & $\mathbf{6}$ & $\mathbf{5}$ & $\mathbf{5}$ & $\mathbf{1 0}$ & $\mathbf{1 0}$ & $\mathbf{8}$ & $\mathbf{8}$ & $\mathbf{8}$ & $\mathbf{8}$ & $\mathbf{8}$ \\
\hline 127 & $\mathbf{6}$ & $\mathbf{5}$ & $\mathbf{5}$ & $\mathbf{1 0}$ & $\mathbf{1 0}$ & $\mathbf{8}$ & $\mathbf{8}$ & $\mathbf{8}$ & $\mathbf{8}$ & $\mathbf{8}$ \\
\hline 128 & $\mathbf{6}$ & $\mathbf{5}$ & $\mathbf{5}$ & $\mathbf{1 0}$ & $\mathbf{1 0}$ & $\mathbf{8}$ & $\mathbf{8}$ & $\mathbf{8}$ & $\mathbf{8}$ & $\mathbf{8}$ \\
\hline 129 & $\mathbf{6}$ & $\mathbf{5}$ & $\mathbf{5}$ & $\mathbf{1 0}$ & $\mathbf{1 0}$ & $\mathbf{1 0}$ & $\mathbf{8}$ & $\mathbf{8}$ & $\mathbf{8}$ & $\mathbf{8}$ \\
\hline 130 & $\mathbf{6}$ & $\mathbf{5}$ & $\mathbf{5}$ & $\mathbf{1 0}$ & $\mathbf{1 0}$ & $\mathbf{1 0}$ & $\mathbf{8}$ & $\mathbf{8}$ & $\mathbf{8}$ & $\mathbf{8}$ \\
\hline
\end{tabular}

Table 6C. Evolution of thermal risk in function of process temperature and LA concentration at a catalyst loading of $0.014 \mathrm{~kg} / \mathrm{L}$ under $35 \mathrm{bar}_{2}$ (Medium Negligible).

\begin{tabular}{|c|c|c|c|c|c|c|c|c|c|c|}
\hline RISK & \multicolumn{10}{|c|}{$[L A] \mathrm{mo} / \mathrm{L}$} \\
\hline$T p{ }^{\circ} \mathrm{C}$ & 0.62 & 1.25 & 1.90 & 2.55 & 3.22 & 3.90 & 4.59 & 5.30 & 6.02 & 6.75 \\
\hline 100 & $\mathbf{6}$ & $\mathbf{6}$ & $\mathbf{6}$ & $\mathbf{1 0}$ & $\mathbf{1 0}$ & $\mathbf{1 0}$ & $\mathbf{1 0}$ & $\mathbf{1 0}$ & $\mathbf{1 0}$ & $\mathbf{1 0}$ \\
\hline 110 & $\mathbf{6}$ & $\mathbf{6}$ & $\mathbf{6}$ & $\mathbf{1 2}$ & $\mathbf{1 0}$ & $\mathbf{1 0}$ & $\mathbf{1 0}$ & $\mathbf{1 0}$ & $\mathbf{1 0}$ & $\mathbf{1 0}$ \\
\hline 115 & $\mathbf{6}$ & $\mathbf{6}$ & $\mathbf{6}$ & $\mathbf{1 2}$ & $\mathbf{1 0}$ & $\mathbf{1 0}$ & $\mathbf{1 0}$ & $\mathbf{1 0}$ & $\mathbf{1 0}$ & $\mathbf{1 0}$ \\
\hline 120 & $\mathbf{6}$ & $\mathbf{6}$ & $\mathbf{6}$ & $\mathbf{1 2}$ & $\mathbf{1 2}$ & $\mathbf{1 2}$ & $\mathbf{1 0}$ & $\mathbf{1 0}$ & $\mathbf{1 0}$ & $\mathbf{1 0}$ \\
\hline 125 & $\mathbf{6}$ & $\mathbf{6}$ & $\mathbf{6}$ & $\mathbf{1 2}$ & $\mathbf{1 2}$ & $\mathbf{1 2}$ & $\mathbf{1 0}$ & $\mathbf{1 0}$ & $\mathbf{1 0}$ & $\mathbf{1 0}$ \\
\hline 126 & $\mathbf{6}$ & $\mathbf{6}$ & $\mathbf{6}$ & $\mathbf{1 2}$ & $\mathbf{1 2}$ & $\mathbf{1 2}$ & $\mathbf{1 2}$ & $\mathbf{1 0}$ & $\mathbf{1 0}$ & $\mathbf{1 0}$ \\
\hline 127 & $\mathbf{6}$ & $\mathbf{6}$ & $\mathbf{6}$ & $\mathbf{1 2}$ & $\mathbf{1 2}$ & $\mathbf{1 2}$ & $\mathbf{1 2}$ & $\mathbf{1 0}$ & $\mathbf{1 0}$ & $\mathbf{1 0}$ \\
\hline 128 & $\mathbf{6}$ & $\mathbf{6}$ & $\mathbf{6}$ & $\mathbf{1 2}$ & $\mathbf{1 2}$ & $\mathbf{1 2}$ & $\mathbf{1 2}$ & $\mathbf{1 0}$ & $\mathbf{1 0}$ & $\mathbf{1 0}$ \\
\hline 129 & $\mathbf{6}$ & $\mathbf{6}$ & $\mathbf{6}$ & $\mathbf{1 2}$ & $\mathbf{1 2}$ & $\mathbf{1 2}$ & $\mathbf{1 2}$ & $\mathbf{1 2}$ & $\mathbf{1 0}$ & $\mathbf{1 0}$ \\
\hline 130 & $\mathbf{6}$ & $\mathbf{6}$ & $\mathbf{6}$ & 12 & $\mathbf{1 2}$ & $\mathbf{1 2}$ & $\mathbf{1 2}$ & $\mathbf{1 2}$ & $\mathbf{1 0}$ & $\mathbf{1 0}$ \\
\hline
\end{tabular}


Table 6D. Evolution of thermal risk in function of process temperature and LA concentration at a catalyst loading of $0.14 \mathrm{~kg} / \mathrm{L}$ under 35 bar $\mathrm{H}_{2}$ (Medium Negligible).

\begin{tabular}{|c|c|c|c|c|c|c|c|c|c|c|}
\hline RISK & \multicolumn{10}{|c|}{$[L A] m o / L$} \\
\hline$T p{ }^{\circ} \mathrm{C}$ & 0.62 & 1.25 & 1.90 & 2.55 & 3.22 & 3.90 & 4.59 & 5.30 & 6.02 & 6.75 \\
\hline 100 & $\mathbf{6}$ & $\mathbf{6}$ & $\mathbf{6}$ & $\mathbf{1 2}$ & $\mathbf{1 2}$ & $\mathbf{1 2}$ & $\mathbf{1 2}$ & $\mathbf{1 2}$ & $\mathbf{1 2}$ & $\mathbf{1 2}$ \\
\hline 110 & $\mathbf{6}$ & $\mathbf{6}$ & $\mathbf{6}$ & $\mathbf{6}$ & $\mathbf{1 2}$ & $\mathbf{1 2}$ & $\mathbf{1 2}$ & $\mathbf{1 2}$ & $\mathbf{1 2}$ & $\mathbf{1 2}$ \\
\hline 115 & $\mathbf{6}$ & $\mathbf{6}$ & $\mathbf{6}$ & $\mathbf{6}$ & $\mathbf{1 2}$ & $\mathbf{1 2}$ & $\mathbf{1 2}$ & $\mathbf{1 2}$ & $\mathbf{1 2}$ & $\mathbf{1 2}$ \\
\hline 120 & $\mathbf{6}$ & $\mathbf{6}$ & $\mathbf{6}$ & $\mathbf{6}$ & $\mathbf{1 2}$ & $\mathbf{1 2}$ & $\mathbf{1 2}$ & $\mathbf{1 2}$ & $\mathbf{1 2}$ & $\mathbf{1 2}$ \\
\hline 125 & $\mathbf{6}$ & $\mathbf{6}$ & $\mathbf{6}$ & $\mathbf{6}$ & $\mathbf{1 2}$ & $\mathbf{1 2}$ & $\mathbf{1 2}$ & $\mathbf{1 2}$ & $\mathbf{1 2}$ & $\mathbf{1 2}$ \\
\hline 126 & $\mathbf{6}$ & $\mathbf{6}$ & $\mathbf{6}$ & $\mathbf{6}$ & $\mathbf{1 2}$ & $\mathbf{1 2}$ & $\mathbf{1 2}$ & $\mathbf{1 2}$ & $\mathbf{1 2}$ & $\mathbf{1 2}$ \\
\hline 127 & $\mathbf{6}$ & $\mathbf{6}$ & $\mathbf{6}$ & $\mathbf{6}$ & $\mathbf{1 2}$ & $\mathbf{1 2}$ & $\mathbf{1 2}$ & $\mathbf{1 2}$ & $\mathbf{1 2}$ & $\mathbf{1 2}$ \\
\hline 128 & $\mathbf{6}$ & $\mathbf{6}$ & $\mathbf{6}$ & $\mathbf{6}$ & $\mathbf{1 2}$ & $\mathbf{1 2}$ & $\mathbf{1 2}$ & $\mathbf{1 2}$ & $\mathbf{1 2}$ & $\mathbf{1 2}$ \\
\hline 129 & $\mathbf{6}$ & $\mathbf{6}$ & $\mathbf{6}$ & $\mathbf{6}$ & $\mathbf{1 2}$ & $\mathbf{1 2}$ & $\mathbf{1 2}$ & $\mathbf{1 2}$ & $\mathbf{1 2}$ & $\mathbf{1 2}$ \\
\hline 130 & $\mathbf{6}$ & $\mathbf{6}$ & $\mathbf{6}$ & $\mathbf{6}$ & $\mathbf{1 2}$ & $\mathbf{1 2}$ & $\mathbf{1 2}$ & $\mathbf{1 2}$ & $\mathbf{1 2}$ & $\mathbf{1 2}$ \\
\hline
\end{tabular}


Table 7A. Evolution of thermal risk in function of process temperature and LA concentration at a catalyst loading of $0.014 \mathrm{~kg} / \mathrm{L}$ under 15 bar H2 (Medium Negligible).

\begin{tabular}{|c|c|c|c|c|c|c|c|c|c|c|}
\hline RISK & \multicolumn{10}{|c|}{$[L A] \mathrm{mo} / \mathrm{L}$} \\
\hline$T p{ }^{\circ} \mathrm{C}$ & 0.62 & 1.25 & 1.90 & 2.55 & 3.22 & 3.90 & 4.59 & 5.30 & 6.02 & 6.75 \\
\hline 100 & $\mathbf{6}$ & $\mathbf{6}$ & $\mathbf{5}$ & $\mathbf{1 0}$ & $\mathbf{1 0}$ & $\mathbf{1 0}$ & $\mathbf{1 0}$ & $\mathbf{1 0}$ & $\mathbf{1 0}$ & $\mathbf{1 0}$ \\
\hline 110 & $\mathbf{6}$ & $\mathbf{6}$ & $\mathbf{5}$ & $\mathbf{1 0}$ & $\mathbf{1 0}$ & $\mathbf{1 0}$ & $\mathbf{1 0}$ & $\mathbf{1 0}$ & $\mathbf{1 0}$ & $\mathbf{1 0}$ \\
\hline 115 & $\mathbf{6}$ & $\mathbf{6}$ & $\mathbf{5}$ & $\mathbf{1 0}$ & $\mathbf{1 0}$ & $\mathbf{1 0}$ & $\mathbf{1 0}$ & $\mathbf{1 0}$ & $\mathbf{1 0}$ & $\mathbf{1 0}$ \\
\hline 120 & $\mathbf{6}$ & $\mathbf{6}$ & $\mathbf{5}$ & $\mathbf{1 0}$ & $\mathbf{1 0}$ & $\mathbf{1 0}$ & $\mathbf{1 0}$ & $\mathbf{1 0}$ & $\mathbf{1 0}$ & $\mathbf{1 0}$ \\
\hline 125 & $\mathbf{6}$ & $\mathbf{6}$ & $\mathbf{6}$ & $\mathbf{1 0}$ & $\mathbf{1 0}$ & $\mathbf{1 0}$ & $\mathbf{1 0}$ & $\mathbf{1 0}$ & $\mathbf{1 0}$ & $\mathbf{1 0}$ \\
\hline 126 & $\mathbf{6}$ & $\mathbf{6}$ & $\mathbf{6}$ & $\mathbf{1 0}$ & $\mathbf{1 0}$ & $\mathbf{1 0}$ & $\mathbf{1 0}$ & $\mathbf{1 0}$ & $\mathbf{1 0}$ & $\mathbf{1 0}$ \\
\hline 127 & $\mathbf{6}$ & $\mathbf{6}$ & $\mathbf{6}$ & $\mathbf{1 0}$ & $\mathbf{1 0}$ & $\mathbf{1 0}$ & $\mathbf{1 0}$ & $\mathbf{1 0}$ & $\mathbf{1 0}$ & $\mathbf{1 0}$ \\
\hline 128 & $\mathbf{6}$ & $\mathbf{6}$ & $\mathbf{6}$ & $\mathbf{1 0}$ & $\mathbf{1 0}$ & $\mathbf{1 0}$ & $\mathbf{1 0}$ & $\mathbf{1 0}$ & $\mathbf{1 0}$ & $\mathbf{1 0}$ \\
\hline 129 & $\mathbf{6}$ & $\mathbf{6}$ & $\mathbf{6}$ & $\mathbf{1 0}$ & $\mathbf{1 0}$ & $\mathbf{1 0}$ & $\mathbf{1 0}$ & $\mathbf{1 0}$ & $\mathbf{1 0}$ & $\mathbf{1 0}$ \\
\hline 130 & $\mathbf{6}$ & $\mathbf{6}$ & $\mathbf{6}$ & $\mathbf{1 0}$ & $\mathbf{1 0}$ & $\mathbf{1 0}$ & $\mathbf{1 0}$ & $\mathbf{1 0}$ & $\mathbf{1 0}$ & $\mathbf{1 0}$ \\
\hline
\end{tabular}

Table 7B. Evolution of thermal risk in function of process temperature and LA concentration at a catalyst loading of $0.014 \mathrm{~kg} / \mathrm{L}$ under 50 bar $\mathrm{H}_{2}$ (Medium Negligible).

\begin{tabular}{|c|c|c|c|c|c|c|c|c|c|c|}
\hline RISK & \multicolumn{10}{|c|}{$[L A] \mathrm{mol} / \mathrm{L}$} \\
\hline$T p{ }^{\circ} \mathrm{C}$ & 0.62 & 1.25 & 1.90 & 2.55 & 3.22 & 3.90 & 4.59 & 5.30 & 6.02 & 6.75 \\
\hline 100 & $\mathbf{6}$ & $\mathbf{6}$ & $\mathbf{6}$ & $\mathbf{1 2}$ & $\mathbf{1 0}$ & $\mathbf{1 0}$ & $\mathbf{1 0}$ & $\mathbf{1 0}$ & $\mathbf{1 0}$ & $\mathbf{1 0}$ \\
\hline 110 & $\mathbf{6}$ & $\mathbf{6}$ & $\mathbf{6}$ & $\mathbf{1 2}$ & $\mathbf{1 2}$ & $\mathbf{1 0}$ & $\mathbf{1 0}$ & $\mathbf{1 0}$ & $\mathbf{1 0}$ & $\mathbf{1 0}$ \\
\hline 115 & $\mathbf{6}$ & $\mathbf{6}$ & $\mathbf{6}$ & $\mathbf{1 2}$ & $\mathbf{1 2}$ & $\mathbf{1 2}$ & $\mathbf{1 2}$ & $\mathbf{1 0}$ & $\mathbf{1 0}$ & $\mathbf{1 0}$ \\
\hline 120 & $\mathbf{6}$ & $\mathbf{6}$ & $\mathbf{6}$ & $\mathbf{1 2}$ & $\mathbf{1 2}$ & $\mathbf{1 2}$ & $\mathbf{1 2}$ & $\mathbf{1 2}$ & $\mathbf{1 2}$ & $\mathbf{1 0}$ \\
\hline 125 & $\mathbf{6}$ & $\mathbf{6}$ & $\mathbf{6}$ & $\mathbf{1 2}$ & $\mathbf{1 2}$ & $\mathbf{1 2}$ & $\mathbf{1 2}$ & $\mathbf{1 2}$ & $\mathbf{1 2}$ & $\mathbf{1 2}$ \\
\hline 126 & $\mathbf{6}$ & $\mathbf{6}$ & $\mathbf{6}$ & $\mathbf{1 2}$ & $\mathbf{1 2}$ & $\mathbf{1 2}$ & $\mathbf{1 2}$ & $\mathbf{1 2}$ & $\mathbf{1 2}$ & $\mathbf{1 2}$ \\
\hline 127 & $\mathbf{6}$ & $\mathbf{6}$ & $\mathbf{6}$ & $\mathbf{1 2}$ & $\mathbf{1 2}$ & $\mathbf{1 2}$ & $\mathbf{1 2}$ & $\mathbf{1 2}$ & $\mathbf{1 2}$ & $\mathbf{1 2}$ \\
\hline 128 & $\mathbf{6}$ & $\mathbf{6}$ & $\mathbf{6}$ & $\mathbf{1 2}$ & $\mathbf{1 2}$ & $\mathbf{1 2}$ & $\mathbf{1 2}$ & $\mathbf{1 2}$ & $\mathbf{1 2}$ & $\mathbf{1 2}$ \\
\hline 129 & $\mathbf{6}$ & $\mathbf{6}$ & $\mathbf{6}$ & $\mathbf{1 2}$ & $\mathbf{1 2}$ & $\mathbf{1 2}$ & $\mathbf{1 2}$ & $\mathbf{1 2}$ & $\mathbf{1 2}$ & $\mathbf{1 2}$ \\
\hline 130 & $\mathbf{6}$ & $\mathbf{6}$ & $\mathbf{6}$ & $\mathbf{1 2}$ & $\mathbf{1 2}$ & $\mathbf{1 2}$ & $\mathbf{1 2}$ & $\mathbf{1 2}$ & $\mathbf{1 2}$ & $\mathbf{1 2}$ \\
\hline
\end{tabular}




\section{CONCLUSIONS}

Prior works have studied the kinetics of hydrogenation of levulinic acid to $\gamma$-valerolactone catalyzed by $\mathrm{Ru} / \mathrm{C}$ in water. However, none of them has discussed the thermal aspect of this reaction system. In this paper, thermal risk assessment of levulinic acid hydrogenation to $\gamma$ valerolactone was performed.

To evaluate the thermal risk of this process, a kinetic model under near-adiabatic condition was developed. Experiments at different operating conditions were performed in a near-adiabatic reactor, i.e., ARSST (advanced reactive system screening tool). A non-linear regression method was used to estimate the kinetic constants using the reaction temperature as an observable. Good agreement between experimental data and the model was obtained.

Based on this model, adiabatic temperature rise $\left(\Delta \mathrm{T}_{\mathrm{ad}}\right)$, which characterizes the severity of the thermal risk and Time-to-Maximum Rate under adiabatic conditions (TMR $\mathrm{Td}_{\mathrm{ad}}$, which characterizes the probability of the thermal risk, were obtained. Different operating conditions including levulinic acid concentration, temperature, catalyst loading and hydrogen pressure were tested for the assessment of this process. It should be noticed that when the catalyst is within the loading range of $0.0014-0.014 \mathrm{~kg} / \mathrm{L}$, LA within the concentration in range of $0.62-6.75 \mathrm{~mol} / \mathrm{L}$, temperature in the range of $100-130^{\circ} \mathrm{C}$ and under 35 bar hydrogen pressure, the thermal risk is medium in the majority of cases and safety barriers should be included to prevent a thermal runaway situation. Elevating hydrogen pressure can also increase the thermal risk. Further work should be focused on determining the optimum operating conditions for this system based on mass and energy balance. Another investigation can also be the establishment of an intrinsic kinetic model taking into account the internal and external mass transfer under adiabatic mode, 
and use a design of experiment methodology to determine the main inlet parameters (catalyst particle size distribution, rotating speed,...) influencing the thermal risk.

\section{EXPERIMENTAL SECTION}

\subsection{Chemicals and analytical methods}

Levulinic acid $(\mathrm{wt} \% \geq 97 \%)$ was purchased from Sigma-Aldrich company. The product $\gamma$ valerolactone (98 wt.\%) was purchased from MERCK company. Ru/C (5\%wt ruthenium on activated carbon powder, reduced and $50 \%$ water wet) was provided by Alfa Aesar company. $\mathrm{H}_{2}(>99.999 \%)$ and $\mathrm{N}_{2}(>99.9 \%)$ were supplied from Linde company. All the chemicals were used without further treatment.

\subsection{Experiments performed in ARSST}

The calorimeter ARSST, standing for advanced reactive system screening tool, was used. This calorimeter works under near-adiabatic conditions under the heat loss compensation principle. ${ }^{52,53}$ Several research groups have used this calorimeter to study exothermic chemical system in liquid phase. ${ }^{42,45,52-57}$ The benefits of this calorimeter are the use of small amount of chemicals, i.e., ca. 10 grams, possibility to work under high pressure to neglect evaporation and fast screening of exothermic reactions. ${ }^{58,59}$

In our experiments, the ARSST was used to record the variation of pressure and temperature for the hydrogenation of levulinic acid to $\gamma$-valerolactone catalyzed by $\mathrm{Ru} / \mathrm{C}$ under near-adiabatic conditions.

This unit consists of two main parts, as shown in Figure 6, one is a $10 \mathrm{~mL}$ glass cell and the other one is a $450 \mathrm{~mL}$ stainless steel reactor that could stand high pressure (maximum pressure 100 
bar). The $10 \mathrm{~mL}$ glass cell includes the reaction mixture and a magnetic stirring bar inside. The cell is surrounded by a heater belt which could provide electrical heating, and insulated by aluminum paper and glass fiber. It is possible to adjust the electrical heating to obtain the desired background heating rates.

A thermocouple $\mathrm{T} 1$ (T1 in Figure 7) is put in contact with the reaction mixture. The $450 \mathrm{~mL}$ stainless steel reactor is linked with hydrogen gas supply system, pressure and temperature monitor. A thermocouple T2 (T2 in Figure 7) is put in the headspace of the stainless steel reactor to record the evolution of temperature in the gas phase.

Before starting the experiment, the $10 \mathrm{~mL}$ glass cell was filled with desired amount of levulinic acid, distilled water and $\mathrm{Ru} / \mathrm{C}$ catalyst. The sealed system was purged with nitrogen then by hydrogen. Then, ca. 35 bar of $\mathrm{H}_{2}$ was supplied into the system as reactant and to minimize the evaporation of the liquid mixture as well.

The process was started without stirring until ca. $60^{\circ} \mathrm{C}$. The aim of this step is to heat the mixture and avoid the start of chemical reaction. Time zero was defined when the stirring started. When the temperature of the mixture reached the maximum temperature, the process was stopped and cooled down. As the variation of recorded pressure was quite low $(<1.4 \%)$, the system can be considered under isobaric conditions. 


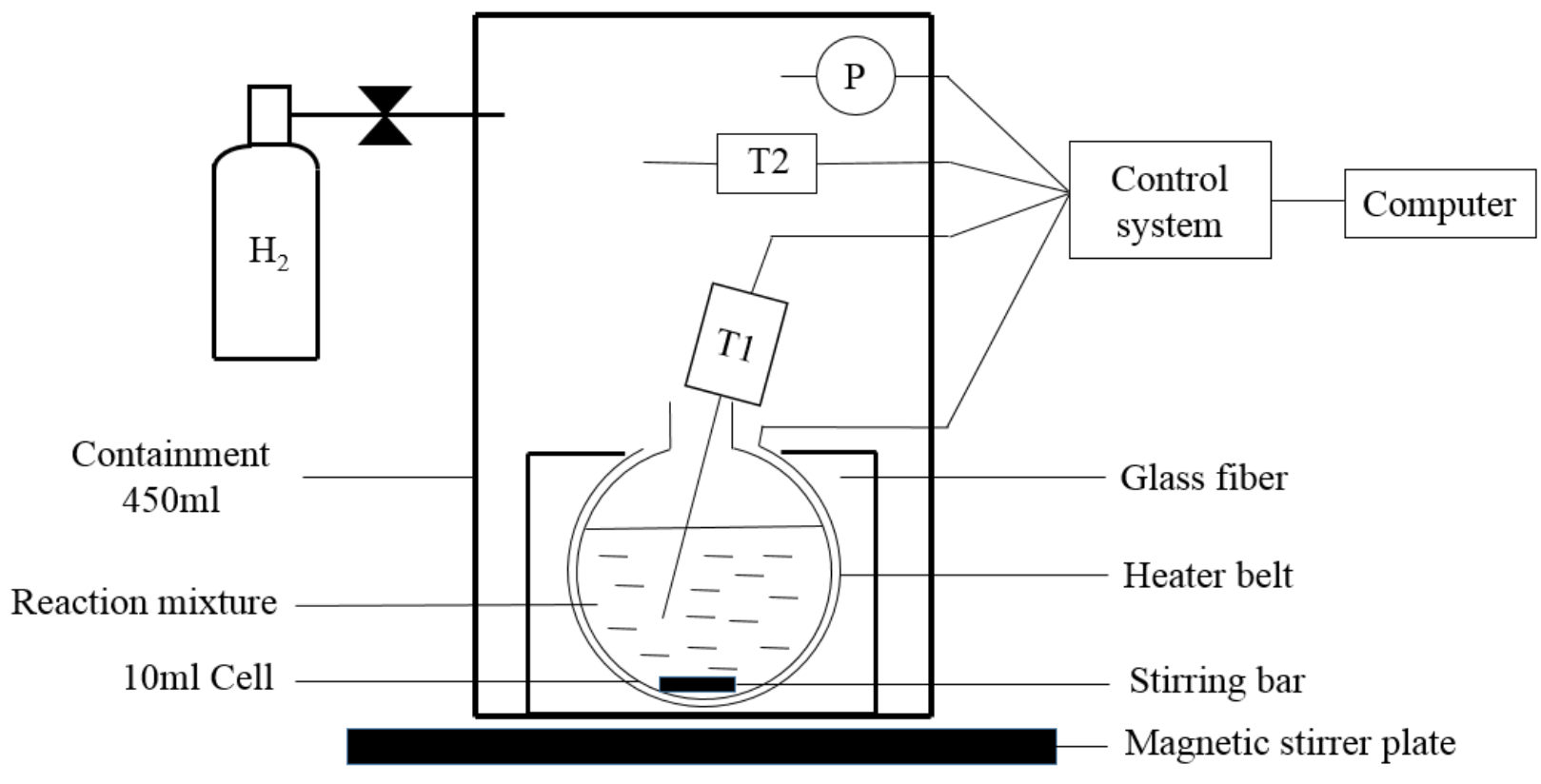

Figure 7. Schematic view of Advanced Reactive System Screening Tool (ARSST). 


\section{ACKNOWLEDGEMENTS}

This study has been done in the framework of Task 2: "Green process: $2^{\text {nd }}$ generation of biomass" of AMED project. The authors thank AMED project. The AMED project has been funded with the support from the European Union with the European Regional Development Fund (ERDF) and from the Regional Council of Normandie.

The authors thank also the PHC program Galileo (37267VC). The China Scholarship Council: Cooperation Program with the UTs and INSAs (France) is thanked by the authors. The authors thank the Maîtrise des Risques et Environementaux department. 


\section{SUPPORTING INFORMATION}

For the sake of conciseness, we have put in supporting information the evolution of specific heatcapacities of water, levulinic acid and $\gamma$-valerolactone. 


\section{NOMENCLATURE}

$C_{P}$

$\mathrm{Ea}$

$\Delta \mathrm{H}_{\mathrm{R}}$

$\mathrm{k}$

$\mathrm{K}_{\mathrm{HPA}}$

$\mathrm{K}_{\mathrm{LA}}$

$\mathrm{K}_{\mathrm{GVL}}$

$K_{L A}^{\text {diss }}$

$K_{H P A}^{\text {diss }}$

$K_{2}$

$\mathrm{V}_{\text {liq }}$

$m_{\text {insert }}$

$\mathrm{m}_{\mathrm{j}}$

$\mathrm{n}_{\mathrm{j}}$

$\mathrm{P}$

qel

$\mathrm{q}_{\mathrm{rx}}$

$\mathrm{R}$

$\mathrm{R}^{2}$

$\Delta \mathrm{T}_{\mathrm{ad}}$

$\mathrm{T}_{1}$
Specific heat-capacity $[\mathrm{J} /(\mathrm{kg} . \mathrm{K})]$

Activation energy $[\mathrm{J} / \mathrm{mol}]$

Reaction enthalpy [J/mol]

Rate constant

Adsorption coefficient of HPA [L/mol]

Adsorption coefficient of LA [L/mol]

Adsorption coefficient of GVL [L/mol]

Dissociation constant of LA [mol/L]

Dissociation constant of HPA [mol/L]

Equilibrium constant

Volume of liquid [L]

Insert mass $[\mathrm{kg}]$

Mass of compound $\mathrm{j}[\mathrm{kg}]$

Number of moles of compound $\mathrm{j}$ [mol]

Pressure [bar]

Electrical heating-rate $[\mathrm{J} / \mathrm{s}]$

Heat-flow rate due to chemical reactions [J/s]

Gas constant [J/(K.mol)]

Coefficient of explanation [\%]

Adiabatic temperature rise $\left[{ }^{\circ} \mathrm{C}\right]$

Temperature of the reaction mixture $\left[{ }^{\circ} \mathrm{C}\right]$ 
$\mathrm{T}_{2}$

$\mathrm{T}_{\text {Ref }}$

$y_{\text {exp }}$

$y_{\text {model }}$

Greek letters

$\beta$

$\omega$

Abbreviations

Temperature in the gas phase $\left[{ }^{\circ} \mathrm{C}\right]$

Reference temperature $\left[{ }^{\circ} \mathrm{C}\right]$

Experimental observable value

Simulated observable value

Objective function

ARSST

LA

LCB

GVL

HMF

$\mathrm{TMR}_{\mathrm{ad}}$
Advanced Reactive System Screening Tool

Levulinic acid

Lignocellulosic biomass

$\gamma$-valerolactone

Hydroxymethylfurfural

Time-to-maximum rate under adiabatic conditions at $\mathrm{T}_{\mathrm{P}}[\mathrm{hrs}]$ 


\section{REFERENCES}

(1) Adib, R.; Murdock, H.; Appavou, F.; Brown, A.; Epp, B.; Leidreiter, A.; Lins, C.; Murdock, H.; Musolino, E.; Petrichenko, K. Renewables 2016 Global Status Report. Renewable Energy policy Network for the $21^{\text {st }}$ century (REN21) 2016, 1-28.

(2) Nakada, S.; Saygin, D.; Gielen, D. Global bioenergy supply and demand projections: a working paper for REmap 2030. International Renewable Energy Agency (IRENA) 2014, 1-88.

(3) Werpy, T.; Petersen, G.; Aden, A.; Bozell, J.; Holladay, J.; White, J.; Manheim, A.; Eliot, D.; Lasure, L.; Jones, S. Top value added chemicals from biomass. Volume 1-Results of screening for potential candidates from sugars and synthesis gas. Department of Energy Washington DC, 2004, 1-67.

(4) Luterbacher, J.; Alonso, D. M.; Dumesic, J. Targeted chemical upgrading of lignocellulosic biomass to platform molecules. Green Chem. 2014, 16 (12), 4816-4838.

(5) Isikgor, F. H.; Becer, C. R. Lignocellulosic biomass: a sustainable platform for the production of bio-based chemicals and polymers. Polym. Chem. 2015, 6 (25), 4497-4559.

(6) Galletti, A. M. R.; Antonetti, C.; De Luise, V.; Licursi, D.; Nassi, N. Levulinic acid production from waste biomass. Bioresources 2012, 7 (2), 1824-1835.

(7) Mukherjee, A.; Dumont, M.-J.; Raghavan, V. Sustainable production of hydroxymethylfurfural and levulinic acid: Challenges and opportunities. Biomass Bioenerg 2015, $72,143-183$.

(8) Fitzpatrick, S. W. Lignocellulose degradation to furfural and levulinic acid. US 4897497, US Patents, 1990.

(9) Fitzpatrick, S. W. Production of levulinic acid from carbohydrate-containing materials. US 5608105, US Patents, 1997. 
(10) Hayes, D. J.; Fitzpatrick, S.; Hayes, M. H.; Ross, J. R. The biofine process-production of levulinic acid, furfural, and formic acid from lignocellulosic feedstocks. Biorefineries-Industrial Processes and Product 2006, 1, 139-164.

(11) Alonso, D. M.; Wettstein, S. G.; Dumesic, J. A. Gamma-valerolactone, a sustainable platform molecule derived from lignocellulosic biomass. Green Chem. 2013, 15 (3), 584-595.

(12) Derle, S. N.; Parikh, P. A. Hydrogenation of levulinic acid and $\gamma$-valerolactone: steps towards biofuels. Biomass Conv. Bioref. 2014, 4 (4), 293-299.

(13) Galletti, A. M. R.; Antonetti, C.; Ribechini, E.; Colombini, M. P.; o Di Nasso, N. N.; Bonari, E. From giant reed to levulinic acid and gamma-valerolactone: a high yield catalytic route to valeric biofuels. Appl. Energ. 2013, 102, 157-162.

(14) Abdelrahman, O. A.; Heyden, A.; Bond, J. Q. Analysis of kinetics and reaction pathways in the aqueous-phase hydrogenation of levulinic acid to form $\gamma$-valerolactone over $\mathrm{Ru} / \mathrm{C}$. $A C S$ Catal. 2014, 4 (4), 1171-1181.

(15) Ortiz-Cervantes, C.; García, J. J. Hydrogenation of levulinic acid to $\gamma$-valerolactone using ruthenium nanoparticles. Inorg. Chim. Acta 2013, 397, 124-128.

(16) Xianlong, D.; Yongmei, L.; Jianqiang, W.; Yong, C.; Kangnian, F. Catalytic conversion of biomass-derived levulinic acid into $\gamma$-valerolactone using iridium nanoparticles supported on carbon nanotubes. Chin. J. Catal. 2013, 34 (5), 993-1001.

(17) Delhomme, C.; Schaper, L.-A.; Zhang-Preße, M.; Raudaschl-Sieber, G.; Weuster-Botz, D.; Kühn, F. E. Catalytic hydrogenation of levulinic acid in aqueous phase. J. Organomet. Chem. 2013, 724, 297-299. 
(18) Chalid, M.; Broekhuis, A.; Heeres, H. Experimental and kinetic modeling studies on the biphasic hydrogenation of levulinic acid to $\gamma$-valerolactone using a homogeneous water-soluble Ru-(TPPTS) catalyst. J. Mol. Catal. A-Chem. 2011, 341 (1), 14-21.

(19) Yan, K.; Chen, A. Efficient hydrogenation of biomass-derived furfural and levulinic acid on the facilely synthesized noble-metal-free $\mathrm{Cu}-\mathrm{Cr}$ catalyst. Energy 2013, 58, 357-363.

(20) Mehdi, H.; Fábos, V.; Tuba, R.; Bodor, A.; Mika, L. T.; Horváth, I. T. Integration of homogeneous and heterogeneous catalytic processes for a multi-step conversion of biomass: from sucrose to levulinic acid, $\gamma$-valerolactone, 1, 4-pentanediol, 2-methyl-tetrahydrofuran, and alkanes. Top. Catal. 2008, 48 (1-4), 49-54.

(21) Deng, L.; Li, J.; Lai, D. M.; Fu, Y.; Guo, Q. X. Catalytic conversion of biomass-derived carbohydrates into $\gamma$-valerolactone without using an external $\mathrm{H}_{2}$ supply. Angew. Chem. Int. Edit. 2009, 48 (35), 6529-6532.

(22) Heeres, H.; Handana, R.; Chunai, D.; Rasrendra, C. B.; Girisuta, B.; Heeres, H. J. Combined dehydration/(transfer)-hydrogenation of C6-sugars (D-glucose and D-fructose) to $\gamma$ valerolactone using ruthenium catalysts. Green Chem. 2009, 11 (8), 1247-1255.

(23) Chia, M.; Dumesic, J. A. Liquid-phase catalytic transfer hydrogenation and cyclization of levulinic acid and its esters to $\gamma$-valerolactone over metal oxide catalysts. Chem. Commun. 2011, 47 (44), 12233-12235.

(24) Tang, X.; Chen, H.; Hu, L.; Hao, W.; Sun, Y.; Zeng, X.; Lin, L.; Liu, S. Conversion of biomass to $\gamma$-valerolactone by catalytic transfer hydrogenation of ethyl levulinate over metal hydroxides. Appl. Catal. B-Environ. 2014, 147, 827-834. 
(25) Upare, P. P.; Lee, J.-M.; Hwang, D. W.; Halligudi, S. B.; Hwang, Y. K.; Chang, J.-S. Selective hydrogenation of levulinic acid to $\gamma$-valerolactone over carbon-supported noble metal catalysts. J. Ind. Eng. chem. 2011, 17 (2), 287-292.

(26) Wettstein, S. G.; Bond, J. Q.; Alonso, D. M.; Pham, H. N.; Datye, A. K.; Dumesic, J. A. RuSn bimetallic catalysts for selective hydrogenation of levulinic acid to $\gamma$-valerolactone. Appl. Catal. B-Environ. 2012, 117, 321-329.

(27) Yan, Z.-p.; Lin, L.; Liu, S. Synthesis of $\gamma$-valerolactone by hydrogenation of biomassderived levulinic acid over Ru/C catalyst. Energy Fuels 2009, 23 (8), 3853-3858.

(28) Huang, B.; Leveneur, S.; Zamar, T.; Mikkola, J.-P.; Taouk, B. Towards Production of $\gamma$ valerolactone via Hydrogenation of Aqueous Levulinic Acid. Int. J. Chem. React. Eng. 2015, 13 (1), 119-127.

(29) Piskun, A.; de Haan, J.; Wilbers, E.; van de Bovenkamp, H.; Tang, Z.; Heeres, H. Hydrogenation of levulinic acid to $\gamma$-valerolactone in water using millimeter sized supported $\mathrm{Ru}$ catalysts in a packed bed reactor. ACS Sustain. Chem. Eng. 2016, 4 (6), 2939-2950.

(30) Stoessel, F.; Fierz, H.; Lerena, P.; Killé, G. Recent developments in the assessment of thermal risks of chemical processes. Org. Process Res. Dev. 1997, 1 (6), 428-434.

(31) Etchells, J. Why reactions run away. Org. Process Res. Dev. 1997, 1 (6), 435-437.

(32) Moreno, V. C.; Cozzani, V. Major accident hazard in bioenergy production. J. Loss Prevent. Proc. 2015, 35, 135-144.

(33) Moreno, V. C.; Papasidero, S.; Scarponi, G. E.; Guglielmi, D.; Cozzani, V. Analysis of accidents in biogas production and upgrading. Renew. Energ. 2016, 96, 1127-1134.

(34) Brown, D. B.; Ironside, M. D.; Shaw, S. M. Safety Notables: Information from the Literature. Org. Process Res. Dev. 2016, 20 (3), 575-582. 
(35) Piskun, A.; Van de Bovenkamp, H.; Rasrendra, C.; Winkelman, J.; Heeres, H. Kinetic modeling of levulinic acid hydrogenation to $\gamma$-valerolactone in water using a carbon supported Ru catalyst. Appl. Catal. A-Gen. 2016, 525, 158-167.

(36) Negahdar, L.; Al-Shaal, M. G.; Holzhäuser, F. J.; Palkovits, R. Kinetic analysis of the catalytic hydrogenation of alkyl levulinates to $\gamma$-valerolactone. Chem. Eng. Sci. 2017, 158, 545551.

(37) Schweitzer, J.-M.; López-García, C.; Ferré, D. Thermal runaway analysis of a threephase reactor for LCO hydrotreatment. Chem. Eng. Sci. 2010, 65 (1), 313-321.

(38) Stoessel, F. Experimental study of thermal hazards during the hydrogenation of aromatic nitro compounds. J. Loss Prevent. Proc. 1993, 6 (2), 79-85.

(39) Vasiliu, M.; Guynn, K.; Dixon, D. A. Prediction of the thermodynamic properties of key products and intermediates from biomass. J. Phys. Chem. C 2011, 115 (31), 15686-15702.

(40) Balasubramanian, S.; Louvar, J. F. Study of major accidents and lessons learned. Process Saf. Prog. 2002, 21 (3), 237-244.

(41) Saada, R.; Patel, D.; Saha, B. Causes and consequences of thermal runaway incidentswill they ever be avoided? Process Saf. Environ. 2015, 97, 109-115.

(42) Vernières-Hassimi, L.; Dakkoune, A.; Abdelouahed, L.; Estel, L.; Leveneur, S. ZeroOrder Versus Intrinsic Kinetics for the Determination of the Time to Maximum Rate under Adiabatic Conditions (TMRad): Application to the Decomposition of Hydrogen Peroxide. Ind. Eng. Chem. Res. 2017, 56 (45), 13040-13049.

(43) Carlson, E. C. Don't gamble with physical properties. Chem. Eng. Prog. 1996, 92(10), 35. 
(44) Chua, H. T.; Chakraborty, A.; Wang, X. L. The Specific Heat Capacity of AdsorbateAdsorbent System. International Refrigeration and Air Conditioning Conference 2004, 1-6.

(45) Leveneur, S. Thermal Safety Assessment through the Concept of Structure-Reactivity: Application to Vegetable Oil Valorization. Org. Process Res. Dev. 2017, 21 (4), 543-550.

(46) Chase, M., Jr.,. NIST-JANAF Thermochemical. J. Phys. Chem. Ref. Data. 1998, Monograph No.9.

(47) Leis, J. R.; Kramer, M. A. Algorithm 658: ODESSA-an ordinary differential equation solver with explicit simultaneous sensitivity analysis. ACM Transactions on Mathematical Software (TOMS) 1988, 14 (1), 61-67.

(48) Haario, H. MODEST User's guide. Profmath Oy, Helsinki 1994.

(49) Wu, X.; Li, X.; King, F.; Xiao, J. Insight into and Practical Application of pH-Controlled Asymmetric Transfer Hydrogenation of Aromatic Ketones in Water. Angew. Chem. 2005, 117 (22), 3473-3477.

(50) Stoessel, F. Thermal safety of chemical processes: risk assessment and process design. John Wiley \& Sons 2008.

(51) Baybutt, P. Guidelines for designing risk matrices. Process Saf. Prog. 2017, 37(1), 4955.

(52) Marco, E.; Cuartielles, S.; Pena, J.; Santamaria, J. Simulation of the decomposition of dicumyl peroxide in an ARSST unit. Thermochim. Acta 2000, 362 (1), 49-55.

(53) Tang, W.; Sarvestani, M.; Wei, X.; Nummy, L. J.; Patel, N.; Narayanan, B.; Byrne, D.; Lee, H.; Yee, N. K.; Senanayake, C. H. Formation of 2-trifluoromethylphenyl Grignard reagent via magnesium-halogen exchange: process safety evaluation and concentration effect. Org. Process Res. Dev. 2009, 13 (6), 1426-1430. 
(54) Veedhi, S.; Sawant, A. Designing a safer process for the reaction of TFA with sodium borohydride in THF by calorimetric technique. J. Therm. Anal. Calorim. 2013, 111 (2), 10931097.

(55) Veedhi, S.; Mishra, V.; Kulkarni, S.; Gorthi, R. Incident investigation on thermal instability of an intermediate using adiabatic calorimeter. J. Therm. Anal. Calorim. 2014, 115 (1), 909-914.

(56) Shimizu, S.; Imamura, Y.; Ueki, T. Incompatibilities between N-Bromosuccinimide and Solvents. Org. Process Res. Dev. 2014, 18(2), 354-358.

(57) Theis, A. E.; Burelbach, J. P.; Askonas, C. F. Safely scale-up processes and accommodate recipe changes. Process Saf. Prog. 2009, 28 (2), 135-140.

(58) Fauske, H. K. Managing chemical reactivity-Minimum best practice. Process Saf. Prog. 2006, 25 (2), 120-129.

(59) Mannan, S. Lees' Process Safety Essentials: Hazard Identification, Assessment and Control. Butterworth-Heinemann, 2013. 